\title{
Nigeria's Energy Poverty: Insights and Implications for Smart Policies and Framework towards a Smart Nigeria Electricity Network
}

\author{
Chukwuka G. Monyei ${ }^{1,2}$, Aderemi O. Adewumi ${ }^{1,4}$, Michael O. Obolo ${ }^{2}$ and Barka Sajou ${ }^{3}$ \\ ${ }^{1}$ Centre for Applied Artificial Intelligence, \\ School of Mathematics, Statistics \& Computer Science, \\ University of KwaZulu-Natal, Durban, South Africa \\ ${ }^{2}$ Researchhubng, Ibadan, Nigeria \\ ${ }^{3}$ Nigeria Infrastructure Advisory Facility (NIAF) \\ ${ }^{4}$ Corresponding author \\ chiejinamonyei@gmail.com, adewumia@ukzn.ac.za, michaeldammy@ymail.com and barkasajou@gmail.com
}

\begin{abstract}
A thorough and exhaustive review of relevant literature and associated works is carried out to critically examine energy poverty in Nigeria with respect to ownership and income. Using the desktop approach and empirical formulas, the persistent failure of public infrastructure like healthcare, education and security to the poor electricity generation, transmission and distribution capacity in the country is examined; alongside current government's contribution to buoying our generation capacity and electricity access through policies and investment. The findings of the review reveal the urgent need for the smart roll out of distributed generation units in order to stimulate and encourage the ongoing diversification of the economy and also the need for a sustainable road map that incorporates the successes of countries faced with similar challenges. This review paper also proposes the need for palliatives in form of subsidized solar home systems (SHSs) through a sustainable and economically viable means for off grid homes to assuage the effects of non-availability of grid electricity.
\end{abstract}

Keywords: -energy poverty, income, electricity network, competent policy, economy, distributed generation

\section{Contents}

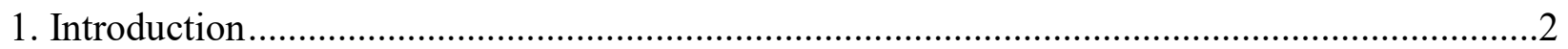

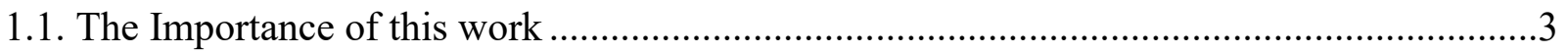

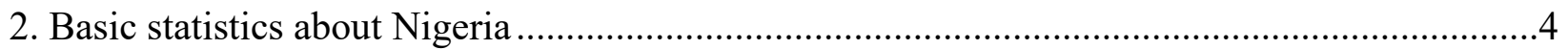

2.1. Growth rate

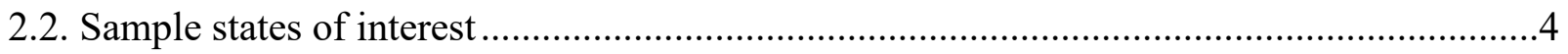

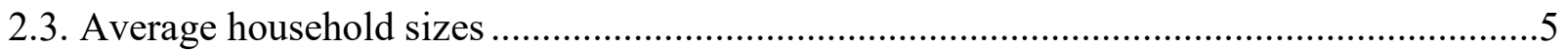

2.4. Households grid connection ......................................................................................

3. Brief history of electricity generation and management in Nigeria...........................................6

3.1. Electricity generation, transmission and distribution ..........................................................

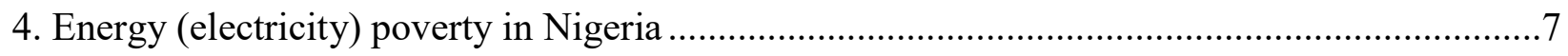

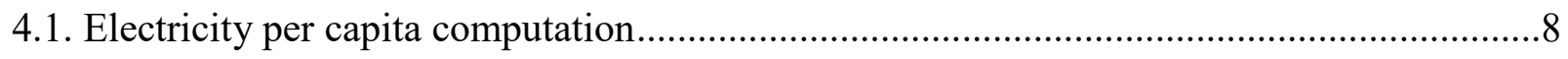

4.2. Households ownership of electronic devices ………........................................................ 
4.3. Categorization of consumers based on ownership ...................................................10

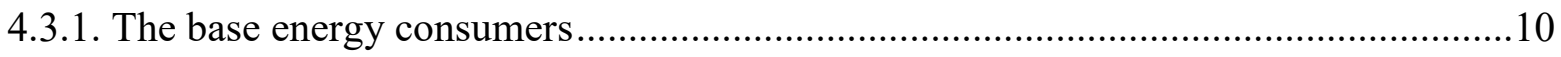

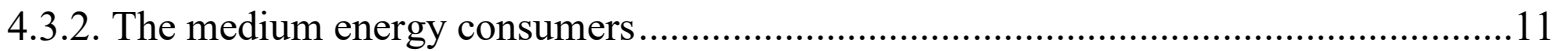

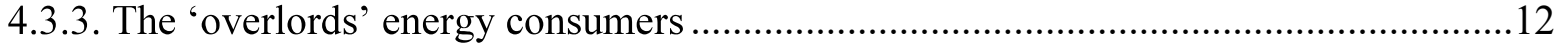

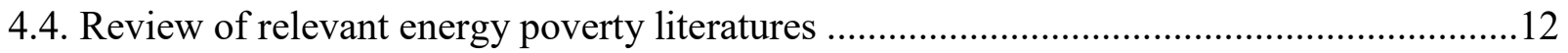

4.5. Installed capacity versus generated capacity scenario ..............................................13

5. Obvious justification for Nigeria's high energy (electricity) poverty ..................................13

6. A brief of Nigeria's renewable energy potentials ............................................................ 15

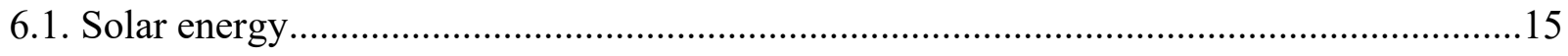

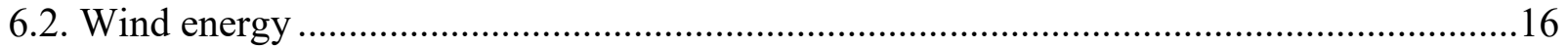

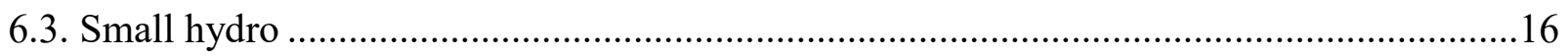

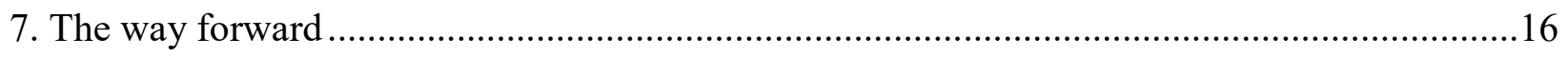

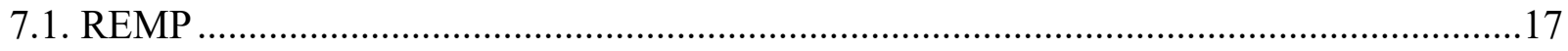

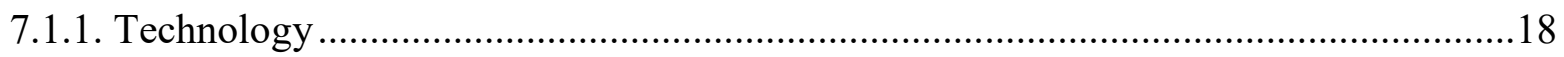

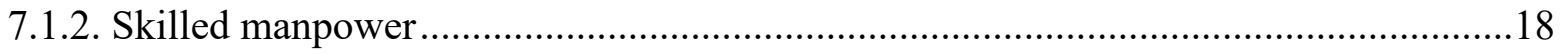

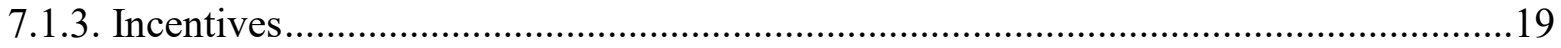

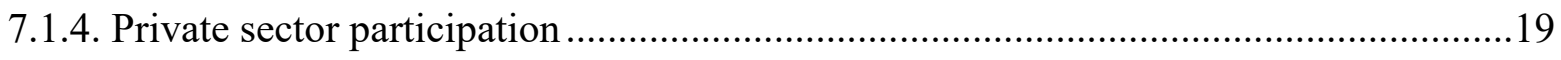

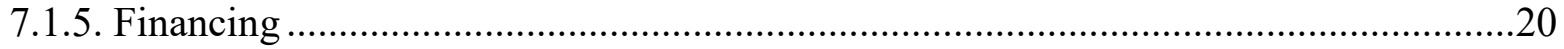

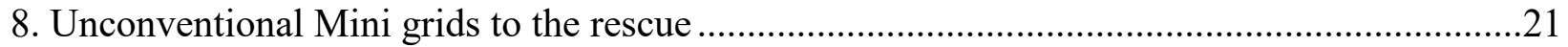

8.1. Energy classification of off grid rural households ....................................................22

8.2. Classification of Solar Home Systems (SHSs) ...........................................................22

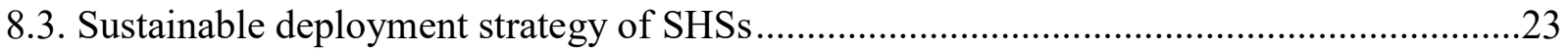

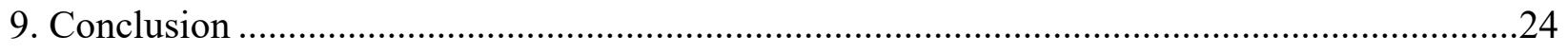

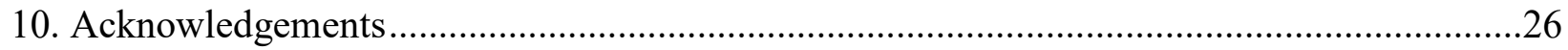

\section{Introduction}

Previous and ongoing literatures have to a large extent presented the state of electricity capacity - generation, transmission and distribution in sub-Sahara Africa (SSA). It has been severally posited that there are over 1 billion people worldwide without access to electricity, with about $85 \%$ of them residing in rural areas in SSA and South Asia [1-3]. The role of energy, though not expressly stated to the success of the Millennium Development Goals (MDGs) was generally established at the World Summit on Sustainable Development (WSSD) held in South Africa in 2002 [4]. It is a common fact that lack of access to modern energy sources has been opined to impede economic and societal development [4-6], thus, the provision of electricity to residents of developing countries is an incentive for improved economic and social development $[7,8]$. 
The inter-relationship between energy and poverty which has been established [9-11] has been shown to be the primary problem of energy security, affecting mostly women and children of developing countries [12]. While high poverty prevalence is known to affect the energy consumption pattern of households, their access to clean and reliable energy is believed to aid in alleviating poverty as increase access to energy allows for more growth economically [13, 14]. Energy poverty therefore for the purpose of this work is defined to be the lack of access to electricity [15], leading to dependence on biomass for meeting cooking and heating needs, a view further corroborated and established as being prevalent in developing countries especially in SSA and Asia [3].

The essentiality and importance of energy to sustainable development [16] and its centrality to modern life notwithstanding, there has been no guaranteed and sustained universal access to energy (electricity) especially in developing countries. For instance, only $13 \%$ of the population of Burma is opined to have access to electricity [17] which pales when compared to the over 80 million Nigerians without access to electricity. This lack of access to electricity is further established by the high percentage of such countries population living in rural communities and below the poverty line. A World Bank report posits that Nigeria's official poverty rate remained at an alarming $62 \%$ (in strictly per capita terms) with another report putting the rural population at $66.67 \%$ of her official population $[18,19]$.

Solutions have been proffered for improved electricity access and delivery to Nigerians. These range from policy change/development [14, 19-28], increased government investments [20, 29], diversification of energy base (to accommodate renewable energy sources) to smart grids [14, 19-21, 23-32], embedded (distributed) generation [14, 19, 20, 23, 25, 26], advanced metering infrastructure etc. These arguments have also basically established energy security, economic growth and carbon emission reductions as underlying factors for a more improved electricity network. However, these proffered solutions have not been able to justify the seemingly low electricity per capita of Nigeria when compared to other SSA, Asian and OECD countries.

\subsection{The importance of this work}

This work therefore seeks to show statistically and through related literature a justification for the low electricity per capita of Nigeria, linking it to income and ownership. It is also further proffered in this work that for an increased electricity access and economic growth, 'individualized and unconventional smart distributed generation and pricing schemes' would be 
a better solution to large/medium distributed generators. This work further critiques some proposed solutions in existing literature and government's continued investment in centralized generation highlighting vis-vis the prevailing economic recession and difficulty in accessing foreign exchange (FOREX).

The rest of the paper is organized as follows: Section 2 presents some statistics about Nigeria. Section 3 briefly presents the history of electricity generation in Nigeria. Section 4 presents and evaluates the electricity poverty in Nigeria. Obvious justifications for Nigeria's high energy poverty are presented in Section 5 while a review of the key renewable energy sources being exploited in Nigeria is presented in section 6. A way forward through the renewable energy master plan (REMP) alongside its supporting structures - technology, skilled manpower, incentives, financing etc. is presented in section 7 while an unconventional mini-grid roll out is proposed in section 8 . The paper is concluded in section 9 .

\section{Basic statistics about Nigeria}

Nigeria lies in the west coast of Africa and occupies a land area of about $923,768 \mathrm{~km}^{2}$ [33] as seen in Table 1. It is also observed from the Table 1 that Nigeria is made up of 36 states grouped into six geo-political zones and one Federal Capital Territory (FCT) as shown in Figure 1. It is further observed from the Table 1 that about $51 \%$ of the nation's population now reside in the urban areas with about $51 \%$ of the population made up of males.

\subsection{Growth rate}

With an estimated growth rate of about 3.2 percent per annum and an average population density of about 150 people per square kilometer, Nigeria is the most populous nation in Africa and the seventh most populous nation worldwide [33]. In meeting her electricity needs are eleven distribution companies (DISCOs) unbundled from the now defunct Power Holding Company of Nigeria (PHCN). Their zone of coverage is depicted in Figure 2.

\subsection{Sample states of interest}

In providing a detailed approach to pertinent issues that contribute to the energy poverty crisis issue in Nigeria, inferences would be drawn from the Federal Capital Territory (FCT) and three representative states from each geo-political zone in the country as shown in Table 2. This thus implies that eighteen states (representing about $50 \%$ of the total states in Nigeria) and the FCT would be used as basis for drawing inferences and making recommendations. 
2.3. Average household sizes

Tables 3 and 4 present the average household size of houses in both the rural and urban areas of the representative states, FCT and Nigeria as a whole. It is observed from the Table 3 that the average household size of northern states is considerably higher than the southern states for both urban and rural households. Religious belief and the high illiteracy level could be attributed to such occurrence. Edo and Delta States as observed from the Table 3 present the lowest household sizes for both rural and urban households and on average.

Table 4 presents the average household size for Nigeria and the FCT. It is observed from the Table 4 that the average household size of FCT compares favourably with states in the north central region. A plot of the average values of the Urban and Rural household sized for the states considered in this paper, the FCT and Nigeria is shown in Figure 3.

\subsection{Households grid connection}

Severally established is the worrisome condition of low grid connection of households in Nigeria. It is estimated that about $10 \%$ of the rural households and about $40 \%$ of the country's total population are currently connected to the grid [29]. This view is further exacerbated when SSA is considered as about 585 million people have no access to electricity with about $85 \%$ of those without access to electricity living in rural areas [28]. Figure 4 presents the percentage of households in states and the FCT connected to the national grid. A critical examination of the figure 4 reveals that most of the states in the south have between $40 \%$ and $80 \%$ of their households connected to the grid with the exception of Ebonyi and Bayelsa States where grid connection is a dismal $12.3 \%$ and $21.6 \%$. The northern states present more shocking results with such states as Taraba, Yobe and Plateau having 2.8\%, 18.1\% and 18.8\% of their households connected to the grid. A reason for this could be attributed to the large land mass of the north and the dispersed nature of residential structures making it extremely uneconomical extending the grid to distant communities in the north. Table 5 presents a detailed breakdown of the different and common means employed by households in guaranteeing electricity access for the selected states under consideration. It is observed from the Table 5 that Lagos State has the highest percentage of its households having access to electricity (at 99.7\%). Taraba (not among the states under consideration) has just about $11.2 \%$ of its households having access to electricity. Another observation worthy of note from Table 5 is the prevalence of private generator use among households. It is easily observed from the table that Lagos State has the highest percentage $(40.9 \%)$ of its households using private generators to complement supply from the national grid. 
It can also be easily deduced from the Table 5 the poor penetration of rural electrification projects in buoying electricity access in the country considering the fact that its use is not common among states of the federation.

This fact is also corroborated by the dismal outing of solar panels in generating electricity for households. With the huge deficit created by the inability of the national grid to effectively service most of the country's population coupled with growing concerns and increased public outcry to the insidious effects of fossil fuel based electricity generation methods and a shift from the conventional centralized system of electricity generation to a decentralized generation system, attention is now being focused on alternative energy sources especially renewables in diversifying the electricity generation base for the purposes of security and reducing climate change $[34,35]$.

3. Brief history of electricity generation and management in Nigeria The history of electricity generation in Nigeria started in 1896 in the city of Lagos. In 1929, the Nigeria Electricity Supply Company (NESCO) started operations in the northern part of the country as an electric utility company with the construction of a hydroelectric power (HEP) station at Kurra near Jos. The establishment of the Electricity Corporation of Nigeria (ECN) in 1951 through an act of parliament was the country's first attempt at coordinating electricity supply and development. The National Electric Power Authority (NEPA) was formed in 1972 as a successor to the Niger Dams Authority (NDA) which was established in 1962 and empowered to further develop the HEP prospects of Nigeria and ECN. As a successor company, NEPA held exclusive ownership and control rights over all the electricity market in Nigeria from generation to transmission, distribution and sales. The exclusive rights notwithstanding and Nigeria's enormous energy reserves, no significant steady and continuous improvements were witnessed from NEPA. This led to the restructuring of the power sector through the Electric Power Sector Reform Act (EPSRA) enacted in 2005 and the establishment of a sector regulator - the Nigerian Electricity Regulatory Commission (NERC). Also, private sector participation was introduced with NERC licenses for the Power Holding Company of Nigeria (PHCN) and Independent Power Projects (IPPs). Furthermore, the New Power Sector roadmap was officially launched in August 2010. Outlined in this roadmap is government's plan to accelerate the reform pace and bring about an improvement on short term service delivery, the establishment of the Presidential Action Committee on Power (PACP) created to remove 'red-tape' and achieve policy consistency and the establishment of the Presidential Task Force on Power (PTFP) for day to day 
planning, developing and driving forward the reform plans for the Nigerian Power Sector. Furthermore, in assisting with the unbundling of PHCN into its successor companies, government has put in place the Nigerian Electricity Liability Management Company (NELMCO) to take over the stranded assets and liabilities of PHCN and the Bulk Trader (NEBT) to act as a broker between the power producers and distribution companies (DisCos) $[29,36,37]$.

\subsection{Electricity generation, transmission and distribution}

The unbundling of PHCN and its reorganization and privatization has resulted in 6 GenCos, 1 TransCo and 11 DisCos. Table 6 presents in details the federal government (FGN) and National integrated power project (NIPP) generating plants (thermal and hydro) alongside their present capacity and projected increment till 2020. The table 6 excludes the capacity of and projected additions for IPPS, oil companies (IOCs) and renewable energy sources.

Under the Renewable Energy Master Plan (REMP) which was produced in 2006 with its overall objective being to articulate a roadmap for national development through the accelerated development and exploitation of renewable energy (RE), the short, medium and long term targeted contribution of RE is shown in Table 7. The distribution of electricity in Nigeria is handled by the DisCos. Table 8 presents the 11 DisCos and their agreed percentage distribution from available generated power based on the multi-year tariff option (MYTO) plan II.

The transmission network of the Nigerian electricity network showing the power flow from the generation stations to the transmission stations and the movement of power between the transmission stations ( $330 \mathrm{kV}$ main) is shown in the Figure 5. It is also observed from the Figure 6 the distance of the transmission lines between transmission stations and the reactive powers (measured in real time for this particular day) at the various stations.

\section{Energy (electricity) poverty in Nigeria}

The concept of energy poverty in Nigeria has been severally dissected and studied by researchers as earlier pointed out. To further buttress earlier cited literature, it is estimated that about 15.3 million households lack access to grid electricity with supply being erratic for those connected to the grid. Table 9 shows the average number of interruptions on the Nigerian grid between Jan 2008 and December 2004 just before the enactment of the EPSRA. The continued growing trend in the poverty incidence in Nigeria is also presented in Table 10 which shows the poverty growth 
in Nigeria for selected years from 1980 to 2010. A strong correlation is observed from the Table 10 between the growing population and the growing poverty incidence. This growing poverty level and low grid connection has thus led to a gradual shift in the usage of electricity (from grid supply) for cooking to heavy dependence on firewood. It is estimated that over $72 \%$ of the country's population depend on firewood for cooking with about $90 \%$ of households in the north depending on firewood for cooking.

Figure 6 presents the pictorial representation of the percentage of households in each state who are on the basis of this work deemed poor (earning less than US\$2 per day). It is observed from the Figure 6 that only the FCT and Lagos State have the lowest poverty rate with $43.3 \%$ and $46.8 \%$ of their households respectively being poor. On the other hand, states such as Edo, Delta, Gombe, Sokoto, Zamfara, Kano, Bayelsa and Rivers have 62.6\%, 62.2\%, 60.1\%, 60.9\%, 65.2\%, $69.7 \%, 61.5 \%$ and $56.1 \%$ respectively of their households poor. States having over $80 \%$ of their households being poor include Ondo (81.89\%), Ekiti (81.1\%), Enugu and Abia (both having $80.7 \%)$, Ebonyi (88.9\%), Katsina (92.8\%), Yobe (94.3\%) etc. A strong correlation is seen to exist between states household poverty prevalence and grid connection (electricity access) for such states as Yobe, Taraba, Borno, Adamawa, Plateau, Katsina and Ebonyi which with very high percentage of their households being poor have low grid electricity access of $18.1 \%, 2.8 \%$, $15.2 \%, 22.6 \%, 18.8 \%, 36.2 \%$ and $12.3 \%$ respectively.

\subsection{Electricity per capita computation}

Table 11 presents a detailed overview of the total energy (MWh) for the years 2007 and 2008 supplied the eleven DISCOs. It is observed from the table that Lagos State is served by two distribution companies - Eko and Ikeja distribution companies and that there was net decrease in the quantity of energy (electricity) supplied the DISCOs at the end of 2008. The computation of the DISCO zone population is a sum total of the individual states population served by the same DISCO. However, Benin Electricity Distribution Company (BEDC) and Ibadan Electricity Distribution Company (IBEDC) both serve Ekiti. Hence, for the purpose of this paper, Ekiti State has been excluded in the computation of the zone population for both BEDC and IBEDC.

The yearly and monthly per capita electricity consumption $(\mathrm{kWh})$ for the different DISCO service zones for the years 2007 and 2008 is presented in Table 12. It is easily observed from the Table 12 that Lagos State (zone) has the highest yearly electricity per capita of $543.49 \mathrm{kWh}$ and $484.17 \mathrm{kWh}$ for 2007 and 2008 with the Yola zone comprising Adamawa, Borno, Taraba and Yobe States having the lowest yearly electricity per capita of about $35.39 \mathrm{kWh}$. A breakdown of 
these figures into their respective daily and hourly per capita electricity consumption is shown in Table 13.

The computation of the yearly, monthly, daily and hourly electricity consumption per capita $\left(E C_{Y P C}, E C_{M P C}, E C_{D P C}\right.$ and $\left.E C_{H P C}\right)$ is shown in the equations (1)-(4).

Given Annual energy supply, $E S_{A T}$ and DisCo Zone Population (DZP) and assuming the following:

- 12 months $=1$ Year

- 30 days $=1$ Month

- 24 hours = 1 Day

Then,

$$
\begin{aligned}
& E C_{Y P C}(k W h)=\frac{\sum E S_{A T}(M W h)}{D Z P} X 1000 \\
& E C_{M P C}(k W h)=\frac{\sum E C_{Y P C}(k W h)}{12} \\
& E C_{D P C}(k W h)=\frac{\sum E C_{M P C}(k W h)}{30} \\
& E C_{H P C}(W h)=\frac{\sum E C_{D P C}(k W h)}{24} X 1000
\end{aligned}
$$

A cursory look at the data presented in Table 13 shows that the hourly electricity unit available to the consumers in the different distribution zones is quite low. It can be deduced from the table that if electricity supply is guaranteed for a full day, the maximum energy (electricity) that can be consumed on hourly basis by a grid connected consumer is about 3.63 Wh (for Yola Zone), $6.30 \mathrm{Wh}$ (for Kano Zone) and 6.69 Wh (for Jos Zone) for the year 2008. The Lagos Zone with hourly consumption of $56.04 \mathrm{Wh}$ for 2008 is the highest in the country. These values are by far grossly inadequate if the ownership of households is to be examined.

\subsection{Households' ownership of electrical devices}

Table 14 presents the access percentage by households to certain basic electrical appliances like radio, television, mobile phones and personal computer (PC) of our selected states of interest cutting across the six (6) geo-political zones of Nigeria. It is easily observed from the Table 14 the high percentage of access of households to radio and mobile phones among the selected states. This high access no doubt can be traced to the cheapness of radios and its availability in different forms spanning from stand-alone transistor radios to mobile phone incorporated radios. 
The high accessibility of households to mobile phones can also be linked to the high proliferation of cheap competitive brands offering same services as main brands with fairly lower quality materials. A breakdown of the access to radio and mobile phones at the rural and urban level shows that about $95.2 \%$ of households in the urban areas have access to radio compared to $90 \%$ of households in rural areas. Similarly, $93.5 \%$ of urban households compared to $65.8 \%$ of rural households have access to mobile phones. The disparity between the rural and urban households' access can be linked to the purchasing power and level of enlightenment of the residents. It is also observed from the Table 14 the low varying (moderate) access of households to television and the PC. While there seems to be a high percentage of households that have access to television from the south, the percentage of households in the north having access to television pales when compared with the statistics from the south. The purchasing power coupled with the low enlightenment of household residents may be a reason for this. While Table 14 highlights the access of households to the considered electrical appliances, Table 15 gives a level based categorization of households based on their collection of basic electrical appliances.

\subsection{Categorization of consumers based on ownership}

Earlier argued was the fact that the hourly electricity energy available for consumers in the different DISCO zones was grossly inadequate if it were to be taken statistically. In order to justify this statement, a load categorization of households based on ownership (not access) of basic electrical appliances is shown in Table 15. It is observed from Table 15 that there are two basic classifications of the loads namely the stand-alone configuration $(C 1-C 10)$ and the combined configuration (C11-C23). While it may not be realistic for a rural household to have only electrical appliances $\mathrm{C} 3, \mathrm{C} 6, \mathrm{C} 7, \mathrm{C} 8, \mathrm{C} 9$ or $\mathrm{C} 10$, it is practical to have as the only electrical appliance such classifications as $\mathrm{C} 1, \mathrm{C} 2, \mathrm{C} 4$ and $\mathrm{C} 5$. The classification C4 represents $414 \mathrm{~W}$ energy saving bulbs (distributed as two for inside uses and two for security lighting) while C5 represents $214 \mathrm{~W}$ energy saving bulbs (distributed as one for inside lighting and one for security lighting).

Three basic households based on range of consumption can easily be deduced from the Table 15 . They include:

\subsubsection{The base energy consumers}

This is made up of all households whose maximum electricity consumption on hourly basis lies between $0-100 \mathrm{Wh}$. They can also be further divided into the following; The entry level base 
energy consumers: made up of all households whose maximum electricity consumption on hourly basis lies between $0-40 \mathrm{Wh}$; the Middle level base energy consumers: made up of all households whose maximum electricity consumption on hourly basis lies between $40-70$ Wh and the maximum level base energy consumers made up of all households whose maximum electricity consumption on hourly basis lies between 70-100 Wh. If an average of 10 hours of continued electricity usage $(100 \mathrm{~W})$ is assumed at 0.8 demand factor (df) and consumption is totaled over a 30-day period, the total electricity consumed is estimated to be about $24 \mathrm{kWh}$. From Table 16, these households fall under the R1 category as classified by the National Electricity Regulatory Commission (NERC) for the Multi-Year Tariff Option (MYTO). At N4 per kWh of electricity consumed, total monthly expenditure by these households falls short of N100 ( $\$ 96$ about US\$0.31 at US $\$ 1=305 \mathrm{Naira}^{1}$ ).

On the contrary, if the value of hourly electricity units available for consumption by households is taken to be the hourly per capita value for 2008 (taken from Table 13) multiplied by the average persons per household, it therefore implies that an household in Oyo State (with an average of 4 persons per household) will have about $66.28 \mathrm{Wh}$ of electricity units per hour, Rivers State (with an average of 4.2 persons per household) will have about $32.21 \mathrm{Wh}$ of electricity units per hour, Kano State (with an average of 6.7 persons per household) will have about 42.21 Wh units of electricity per hour and Lagos (with an average of 4 persons per household) will have about $224.16 \mathrm{Wh}$ units of electricity units per hour.

A consequence of the above implies that all the states listed above (Oyo, Rivers, Kano and Lagos) will be able to support the entry level base energy consumers, Lagos and Oyo (to some extent) will be able to meet the electricity needs of the middle level base energy consumers while only Lagos State will be able to meet the electricity needs of the maximum level base energy consumers.

\subsubsection{The medium energy consumers}

This represents all households whose hourly electricity consumption lies between $100 \mathrm{Wh}$ and 500 Wh. Just like the base energy consumers, these can also be further sub-classified into three groups namely; The entry level medium energy consumers: made up of all households whose electricity consumption is between $100-150 \mathrm{Wh}$; the sufficient level medium entry consumers: made up of all households having hourly electricity consumption between $150-350 \mathrm{Wh}$ and the luxury level medium energy consumers where the households have hourly electricity

\footnotetext{
1 Central Bank of Nigeria (CBN) Official rate from https://www.cbn.gov.ng/rates/ExchRateByCurrency.asp accessed 19/02/2017
} 
consumption between $350-500 \mathrm{Wh}$. For the states considered (including those of interest), only Lagos State and the FCT may be able to meet the electricity needs of the entry level medium energy consumers with Lagos State being able to meet part of the electricity needs of the sufficient level medium entry consumers. No state including the FCT may be able to meet statistically the electricity needs of the luxury level medium energy consumers.

\subsubsection{The 'overlords' energy consumers}

This group represents all such electricity consumers whose hourly electricity needs surpasses $\mathbf{5 0 0}$ Wh. With sufficient income, they are able to acquire certain basic electrical appliances (considered luxurious under the rural setting owing to income level) that offer them a higher standard of living.

Table 16 presents the classification of electricity consumers based on value of consumption (as a result of ownership of electrical appliances) by the National Electricity Regulatory Commission (NERC). It is easily observed from the Table 16 two broad classes - R1 (customers whose electricity consumption is below $50 \mathrm{kWh}$ per month) and R2 (customers whose electricity consumption exceeds $50 \mathrm{kWh}$ on monthly basis). Generally, R1 customers typically have one fan, one radio and about $2-3$ light bulbs $(\mathrm{C} 1+\mathrm{C} 3+\mathrm{C} 5)$. Majority of households (in the urban areas) fall under this category. It is also observed from the Table 16 the absence of fixed monthly charge ( $\boldsymbol{M}_{\boldsymbol{f}}$ in Naira) and a flat rate electricity price per unit $\left(\mathbf{P}_{\mathbf{u}}\right.$ in $\left.\mathbf{A} / \boldsymbol{k} \boldsymbol{W h}\right)$ of $\mathrm{N} 4$ for the R1 customers.

\subsection{Review of relevant energy poverty literature}

There have been enormous contributions in terms of literature detailing suggestions, results from simulations and actual experiments carried out, policy contributions etc. by authors to the (electric) power sector and its reforms in Nigeria (and developing countries). Table 17 details a review of some of these articles and their potential contribution to the problem of energy access in Nigeria (and developing countries). Reiterated from the Table 17 is the fact that Nigeria's energy poverty is enormous and far supersedes that of other African countries. As can be seen from the Table 18, Nigeria has the lowest electrification rate ( $46 \%$ as at 2005 est.) compared to South Africa (70\% as at 2005 est.), Egypt (98\% as at 2005 est.) and Algeria ( $98.1 \%$ as at 2005 est.) [26]. Although, it may be argued that Nigeria's population far exceeds that of South Africa, Algeria and Egypt, Egypt has about 73.9 million citizens with about 72.4 million electrified residents compared to Nigeria with just about 131.6 million citizens and about 60.5 million 
electrified residents (2005 estimates). It is also observed from the Table 19 that Egypt, South Africa and Algeria all have land areas bigger than that of Nigeria thus eliminating land size and terrain as reasons for low grid connection especially in the rural areas.

\subsection{Installed versus generated capacity scenario}

A major contribution to the low per capita electricity as already computed for Nigeria is the widening margin between generation installed capacity and its capacity utilization in terms of generation. Table 20 presents the installed capacity, generated electricity and utilization of the electricity sector in Nigeria. A steady growth of the installed capacity of the Nigeria power sector can be observed especially during 1990 when about $1000 \mathrm{MW}$ in terms of installed capacity was added to the generation sector. The steady increase in generation capacity nonetheless, there was a marked and upward trend in the distribution losses owing mainly to aging conductors, vandalism and thefts. The distribution loss peaked at 47\% (year 1996) before crashing to about 9\% (in 2008) [25]. Figure 7 presents an illustrative view of the increment in installed capacity and a comparison between the net generation and the distribution loss.

It can thus be inferred from the Table 17 and from preceding authors considered in this review work that the conventional means of electricity generation for Nigeria (fossil fuel based generation) and the centralized means of electricity generation would no longer be able to facilitate an aggressive electrification of distant communities and foster industrialization.

It is thus argued that with the growing trend as regards the widening disparity between installed generation capacity and generation utilization; there could be a worsening of the electricity per capita for Nigeria considering the projected electricity demand (from the REMP) under four economic growth scenarios (7\%,10\%, 11.5\% and 13\%) between 2005 and 2030 as shown in Table 21 and Figure 8.

The distribution of available electricity among the various sectors for Nigeria shown in Table 22 is thus a basis for serious concern and research focus considering the low allocation to the industry sector.

\section{Obvious justification for Nigeria's high energy poverty}

Having successfully presented the energy (electricity) scenario in Nigeria, it is important to note the following: 
I. The idea of having a generalized value for the electricity per capita for Nigeria does not give a true and holistic view to the huge disparity in grid (electricity) access in Nigeria. As earlier pointed out, a huge percentage of households in the northern part of Nigeria are not connected to the grid compared to states in the south. Although, it has been generally stated that the terrain and huge costs of grid expansion especially to the northern rural areas have been underlying reasons for this, however, Egypt and Algeria with similar and worse terrains and with larger land areas than Nigeria, have a greater percentage of their population electrified.

II. About $70 \%$ of Nigerians are poor. With extremely low income and increasing costs of goods and services, households' income is thinly spread among competing needs leaving almost nothing for electricity grid payment if any. Figure 9 shows the household energy use profile for urban areas. It is observed from Figure 9 that firewood usage has the highest at $56 \%$ followed by kerosene (27\%) and charcoal (6\%). The distribution of firewood dependency within Nigeria as seen in Figure 10 shows that it is mostly used in the north for cooking purposes compared to households in the south.

III. The need for electricity (and increased electricity consumption) is based solely on households' electricity demand which is to a large extent fueled by the ownership level of electrical appliances. As earlier shown in the electrical appliances categorization, R1 category under which the rural poor fall can have at most a phone, transistor radio, 2 lighting points and a table/ceiling fan. With the mobile phone and transistor radio being common and the lighting points likely possible, the table/ceiling fan may be a luxury for most considering its initial purchase cost (US\$6.56 - US $\$ 14.75$ at US $\$ 1 / \mathrm{A} 305)^{2}$.

IV. The huge disparity between installed capacity and utilization (net generation) means industries and households have to resort to self-generation. In a 2009 report, selfgeneration from diesel and petrol generators was conservatively estimated at a minimum value of $6000 \mathrm{MW}$. It was further estimated in the report that the poor without access to electricity pay as high as $\mathrm{A} 80 / \mathrm{kWh}$ burning candles and kerosene.

\footnotetext{
${ }^{2}$ An additional inflation rate ranging from $20 \%-50 \%$ should be added to compensate for the increased cost of imported consumer goods into Nigeria owing to low FOREX supply.
} 
V. The huge losses recorded on our transmission network which at a time peaked at $47 \%$ of total generation implies that just about $50 \%$ of generated electricity is available for distribution to grid connected households. This results in low income by the distribution companies and low or no return on investments (ROI) leading to reduced incentives (in terms of increased financing) for an aggressive rural push.

VI. The absence of an overarching pro-poor policy from the DisCos [42] due to lack of comprehensive customer enumeration [43] prevents DisCos from evolving sustainable and economically viable electricity distribution initiatives that ensure protection of the very poor customers and high return on investment (ROI). This has resulted in $29 \%$ of connected consumers opting for disconnection from the national grid in a recent survey [42].

6. A brief of Nigeria's renewable energy potentials

Very briefly in this section, solar, wind and hydro potentials are to be discussed. The discussion ranges from a general overview of their measurement and applications/ongoing utilization projects (if any) in the country.

\subsection{Solar energy}

Nigeria lies between latitude $4^{0} \mathrm{~N}$ and $14^{0} \mathrm{~N}$ and is endowed with sufficient solar radiation [44] making solar photovoltaic (PV) attractive as a source of electric power to providing basic services such as lighting, powering a remote village (village electrification), generating power for rural clinics and [public] schools, vaccine refrigeration, traffic lighting and pumping of clean drinking water $[38,45]$. Also, renewable energy sources (like solar) are becoming much sought after due to their low carbon emissions and the eco-efficient solutions they can provide for developed and developing countries [34]. With average sunshine duration of about 6.25h/day and an annual average solar radiation of about $5.25 \mathrm{~kW} \mathrm{~h} / \mathrm{m}^{2}$ day, Nigeria possesses enormous solar potentials that can be utilized for cooking, heating and drying $[44,46]$. It is also observed from Table 23 the minimum, maximum and mean variation in solar radiation potential for the different months in Nigeria. This is further described pictorially by the Figure 11 where the minimum, maximum and mean plots for yearly solar radiation potential $\left(\mathrm{kW} \mathrm{h} / \mathrm{m}^{2}\right.$ day) for Nigeria is shown. 
The solar potential inherent in Nigeria is further corroborated in $[46,47]$ where the author posits that about $6 \mathrm{MWh}$ of electricity could be produced and consumed in Nigeria on a daily basis if just about $0.1 \%$ of our land area is utilized. Some other ingenious deployments of devices harnessing solar energy include the rooftop solar home systems (SHS), solar lanterns etc.

Observed from Table 24 is the proposed target of the REMP on the contribution of solar PV and solar thermal to the electricity generation capacity of Nigeria.

Some pilot schemes/projects undertaken by the Energy Commission of Nigeria (ECN) and other research bodies utilizing/harnessing solar energy potential are shown in Table 25. It should be noted that most of the projects considered are situated in the northern part of Nigeria. Furthermore, it is estimated that the installed solar PV capacity in Nigeria is in excess of about $350 \mathrm{kWp}$.

\subsection{Wind energy}

While much work has been done on wind energy potential in Nigeria, its potentials have yet to be fully harnessed in the country. The $5 \mathrm{~kW}$ aero-generator used to supply electricity to Sayya Gidan Gada Village in Sokoto is one of the examples of wind projects in Nigeria.

\subsection{Small hydro}

The potentials of small hydro projects in Nigeria are presented in table 26. It is easily observed from the Table 26 that small hydro projects are yet to be fully exploited in Nigeria considering the fact that only about $4 \%$ of the total capacity of the under listed hydro sites has been developed. Compared to the larger hydro projects which are costly in setting up and not flexible in dispatch considering their long start up and shut down time, small hydro projects offer flexibility and easy scalability especially in dispatch. The large hydro-electric power (HEP) stations are estimated to have contributed about $39 \%$ of the total grid electricity produced in Nigeria between 1999 and 2004 with the bulk of generation spread across Kainji HEP (760 MW), Jebba HEP (578 MW) and Shiroro HEP (600 MW). The classification of small HEP stations is shown in the Table 27.

\section{The way forward}

In a recent work by [48], the concept of load partitioning was proposed as a viable means to increasing the penetration of solar energy in Nigeria. However, while it can be agreed with the 
authors that lighting has the highest impact on the quality of life of Nigerians, we disagree with the proposed load partitions being adopted by the authors considering that a majority of the electrical equipment considered in the various classes are only available to a few of the urban population and scarcely available throughout rural households, a position justified by the ownership of electrical equipment by Nigerians and the poverty index in Nigeria. Similarly, the idea of deploying SHS based on pre-classified load partition forces consumers to remain at a level due to the often huge costs of upgrading. This way, growth and productivity are discouraged since status and comfort cannot be increased.

Critically argued and established has been the fact that the backbone to the success of any electrification policy thrust by a government is the collection of sound statistical data which is useful in effectively mapping out the electrification needs of the country. In providing solutions to the problem of energy poverty through the deployment of DG, we critique exhaustively while juxtaposing available and prevailing government policies within the REMP with that of select countries in Asia.

\subsection{The REMP}

The REMP which details the exploitation of RE in the country is yet to be fully backed up by law. A thorough examination of the policy shows that in the short term, RE contribution to total generation is targeted at $13 \%$ of total installed capacity of $16000 \mathrm{MW}$. While this may sound ambitious, it pales when compared to Malaysia's targeted $350 \mathrm{MW}$ of grid connected renewable energy electricity generation as at 2010 in addition to its $99 \%$ electrification rate. China also has witnessed a significant growth in the penetration and deployment of RE especially wind with its installed capacity increasing from about $28 \mathrm{MW}$ in 1996 to about $42 \mathrm{GW}$ in 2010 to become the world's largest wind power capacity nation. This shows that rather than paying mere lip service to the Renewable Energy Law of 2005, there has been an aggressive push by the government in increasing the contribution of renewable energy to its energy mix. Furthermore, China has achieved remarkable success in solar water heaters by becoming the world's largest market ensured by consistent long term national goals ensured by means of exemptions, tax rebates, credit guarantees, preferential pricing etc.

The REMP which was produced with support from the UNDP articulates Nigeria's vision for achieving sustainable development and provides a viable road map to achieving this vision with RE. It further envisions a Nigerian economy gradually morphing from a monolithic fossil economy to one driven primarily by an energy base having a large mix of RE that are fully exploited in quantities and at prices that can promote the achievement of an equitable and 
sustainable growth profile [47]. However, several factors seem to impede the full maximization and exploitation of the REMP in Nigeria. A few of them are highlighted subsequently.

\subsubsection{Technology}

A sustainable approach to the dispatch of DGs in remote/off grid communities therefore calls for specific deployment since not all electrification policies target rural households. Other considered customers could be farmers, small or large communities, fishing communities etc. all of which require different technologies. It will thus be important to exploit the best and optimal technology platform that will maximally suit the considered community based on prevailing RES available in the area, the potential of the available RES, cost of setup and long term benefits, the feasibility of hybrid options, the demand profile of the community etc. rather than a one size suits all policy. Similarly, the deployment of the appropriate DG should also be poised to accommodate future increased demand and interconnection with other systems. The smart and sustainable deployment of appropriate DG has led to $100 \%, 99 \%, 99 \%$ and $89 \%$ electrification rates in Singapore, Malaysia, Thailand and Vietnam [49]. Other modern trends like demand side management (DSM) $)^{3}$ should be adopted to help reduce the operational costs of RE integration [50].

\subsubsection{Skilled manpower}

The importance of a skilled workforce capable of handling RE, its operation, utilization and integration with consistent standards and procedures cannot be overemphasized. In recognizing that the development of industrial skills is one of the most critical issues facing Nigeria today, the Nigeria Industrial Revolution Plan (NIPR) aims at addressing this especially the Technical and Vocational Education (TVET) by matching industrial skills development to industry needs and enhancing industrial skills development levels to minimum international standards [51]. While this is a good plan as it aims at positioning the country to be among the most developed 20 countries by 2020 (the vision 20:2020), instability in government owing to the recent transition ${ }^{4}$ in leadership of Nigeria means such lofty plans may be shelved or abandoned. It thus becomes necessary that the core responsibility of developing capacity as regards manpower skills be shifted solely to institutions backed up by law running independent of current government but

\footnotetext{
${ }^{3}$ DSM could be defined as the planning, implementation and monitoring of the activities of utility companies and are designed to the electricity usage patterns of consumers. They include such measures as load shifting, peak shaving etc.

${ }^{4}$ The recent elections in Nigeria (April 2015) unseated the incumbent government and brought in the opposition.
} 
having policies in tandem with national development. Also, such institutions should have their funding consolidated (backed up by law and separate from the executive arm of government). This way they can't be muzzled or intimated by political office holders through arms twisting or stifling of funds.

\subsubsection{Incentives}

The cost of electrification, especially off grid communities and rural areas is a huge one. As a capital intensive project as such, the support of government is essential to the development of a successful electrification plan (whether rural or urban) as a successful electrification program will need long term strategic planning coupled with financial resources for a smooth implementation, maintenance and repairs etc. in the long run. While the participation of the private sector cannot be overemphasized especially in the electrification of far and remote villages through the deployment of stand-alone systems, government intervention in defraying (or subsidizing) some initial costs like connection (including wiring), metering and initial purchase would not only empower the consumers to adopt the new technology being proposed but also provide an enabling and thriving market for the private sector.

In Kenya for example, there is tax exemption for all imported LED-lighting equipment and solar components thus encouraging the local assembly of solar products and solar pico-powered lighting system (PLS). Similarly, the implementation of a $45 \%$ subsidy on all solar equipment as part of its energy for rural transformation (ERT) program has encouraged suppliers of solar equipment to invest in rural areas. In reducing the cost of purchase for PLS equipment, the Ethiopian government has put in place policy that provides for the exemption of solar equipment from inland duties and surtaxes [52]. The Nigerian government could borrow a leaf from these countries in providing competent policy measures that would encourage the proliferation of RE by highly subsidizing renewable energy technologies (RETs) and exempting them taxes. This would definitely force a drastic reduction in their prices and encourage consumers to consider them as viable alternatives since the technology transfer cost would have been eliminated or at best lowered.

\subsubsection{Private sector participation}

The importance of the private sector in buoying the penetration of RETs cannot be overemphasized. Leveraging on favourable government policies and an enabling environment, private industries have been known to contribute favourably to the overall electricity consumption per capita of a country. In Nigeria for example, the Bonny Utility Company (BUC) 
provides us insight into how this could be possible. As a mini-utility company operating in Bonny Island, BUC started as a corporate social responsibility (CSR) of the Nigeria Liquefied Natural Gas (NLNG) who took advantage of a decree by the government permitting private power generation. With a progressive tariff schedule, low income households to larger service sector businesses receive an indirect subsidy ranging from zero (0) percent to about $70 \%$. Here, on Bonny Island and contrary to conventional market practices, low consumption consumers are subsidized by the heavy consumers. Currently serving about 9, 300 customers (corresponding to about 75,000 people), revenue has increased from a monthly accrual of $\$ 37,000$ to an annual collection of about $\$ 500,000$ in 2010 and a projection collection of about $\$ 1.9$ million in 2015. The articulated and clear vision of the company has seen over 5 years of disturbance free operation of this initiative with about $98 \%$ power availability and a significant increase in annual electricity per capita consumption from under $250 \mathrm{kWh}$ to $960 \mathrm{kWh}$ [52]. Other independent power projects (IPPs) of the oil and gas companies include the Okpai power plant by NAOC with installed capacity (as at March 2012) of 480 MW and the Afam VI power plant by SPDC with installed capacity (as at March 2012) of $650 \mathrm{MW}$. Other private interventions should be encouraged by the government that would exploit the available RE resources at regional areas to boost the electricity per capita and stimulate economic growth. Policy intervention by the government could also mandate maximum purchase of electricity generated from RE (set up by private companies) by the NEBT.

\subsubsection{Financing}

Finance plays a dominant role in the proliferation of RETs as it facilitates virtually every preceding item discussed. The recent financial meltdown, reduced income stream owing to the crash of oil prices (as a result of oil glut), increasing budgetary expenditure on recurrent and capital expenditure and the recurrent exposure of financial institutions in the country due to bad loans and unrecovered debts means financing long term RETs by these institutions may be difficult. On the other hand, the inability of the rural dwellers and concerned communities to have in place strong community based organizations (CBOs) that are registered with competent leadership and administration to ensure easy monitoring and efficient recovery means that these communities cannot access loans and other financing opportunities from micro finance institutions (MFIs). The savings and credit co-operative (SACCO), the rotating savings and credit association (ROSCA), village savings load associations and Susu collectors are some examples of semi-formal financing CBOs being exploited in developing nations. For example, the partnership between the self-employed women's association (SEWA) and the International 
Finance Corporation (IFC) has led to the provision of solar lanterns to about 200, 000 rural women members in Gujarat. This was made possible by loans (between US\$ 100 - US\$ 150) provided by IFC through SEWA to the women at about $16 \%$ interest rate with a manageable and flexible monthly repayment plan. The Women Enterprise Development Institute (WEDI) in Kenya was similarly responsible for the distribution of lighting products to its members and the collection of payments. The payroll financing scheme was also instrumental in the provision and distribution of PLS and solar lanterns to employees of the Andhra Pradesh State Transport Corporation (APSTC) in India [53]. Government should as a matter of priority mandate employees at its ministries, departments and agencies (MDAs) to have co-operative societies and provide for their registration. These co-operatives should be tasked with keying into the government's vision for RE by encouraging the proliferation of RETs among its members. Rather than acting as a repository of funds for supporting less meaningful and unsustainable projects, accumulated funds should be used in accessing larger funds or backings to purchase these RETs at even cheaper prices. Furthermore, rural enlightenment and campaign programs are to be sponsored by government and private organizations educating the rural folks on the benefits of forming co-operatives and registering same with the government. This way, huge funds could be accessed even in very remote locations.

8. Unconventional Mini-grids to the rescue

The REMP which has been exhaustively critiqued was among other things poised to:

$>$ Gradually move the Nigerian economy from a monolithic fossil economy to one that is driven by an increasing share of renewable energy.

> Exploit renewable energy in quantities and at prices capable of promoting the achievement of equitable and sustainable growth.

$>$ Encourage the transition from crude oil to a less carbon intensive economy that depends on an increasing contribution from gas and renewable energy.

Furthermore, a cursory look at the projections in the short, medium and long term for the development of generation capacity shows that more emphasis is placed on hydro-electric power (HEP) compared to other RE sources. A demerit of this is based on the fact that increasing the generation capacity would not literally translate to an increment in available power owing to the inability of the existing transmission network to wheel out additional capacity beyond 4, 800 MW which is the current wheeling capacity of the transmission network [54]. Additionally, the current economic recession which Nigeria is currently going through and the difficulty in 
sourcing for FOREX make it almost near impossible for any meaningful work to be done on improving the transmission network which is estimated to cost around US\$8 billion. Frugal and more economically viable options are thus needed in increasing access to the off grid rural communities.

Mini-grids (a form of decentralizing electricity supply) have been instrumental in increasing access to electricity in most rural and off grid communities in sub-Saharan Africa and Asia. Mini-grids in addition to expanding grid access are also economically viable in view of innovations and declining costs. However, there is a need for an immediate deployment of palliatives to off-grid rural communities to stimulate and fast track economic development pending the resolutions of conflicting contractual and funding issues hampering decentralization initiatives. A ready solution that has been tested and is increasingly being deployed across homes in many rural off grid communities in Africa and Asia is the solar home system (SHS). In proposing its deployment, the following steps are further suggested to be taken to ensure the sustainability of the project.

8.1. Energy classification of off grid rural households

As shown in section 4.3, the classification of rural households (based on ownership) reveals the following classes:

- The Entry Level Base Energy Consumers (ELBEC)

- The Medium Level Base Energy Consumers (MLBEC)

- The Maximum Level Base Energy Consumers (MxLBEC)

- The Entry Level Medium Energy Consumers (ELMEC)

- The Sufficient Level Medium Energy Consumers (SLMEC)

- The Luxury Level Medium Energy Consumers (LLMEC)

- The Overlords (OL)

\subsection{Classification of Solar Home Systems (SHSs)}

The classification (energy supply rating) of the SHSs is done in such a way as to reduce wastage. This is achieved through the wide margin across the various proposed SHS models and the cost of upgrading from one energy level (class) to another. Thus, home-owners aim to fully maximize purchased SHS by increasing ownership of necessary electrical appliances that contribute to an 
improvement in their quality of life (QoL). Five classifications are thus proposed for the SHSs namely:

- $90 \mathrm{Wp}(\mathrm{CL} 1)$

- $120 \mathrm{Wp}(\mathrm{CL} 2)$

- $300 \mathrm{Wp}(\mathrm{CL} 3)$

- $400 \mathrm{Wp}(\mathrm{CL} 4)$

- $550 \mathrm{Wp}(\mathrm{CL} 5)$

\subsection{Sustainable deployment strategy of SHSs}

The Figure 12 presents a proposed strategy which is modified from a similar model used in Ghana [55] that is both sustainable and economically viable for the deployment of the SHSs. It is observed from the Figure 12 the source of funding which could be a long term zero interest loan agreement between the national government and international financial corporations (IFC's) like the World Bank (WB) etc. The Ministry of Finance (MoFA) and the Central Bank of Nigeria $(\mathrm{CBN})$ act as the primary conduit for ratifying the agreement and accessing the funds respectively. The deposit money banks (DMBs) and the microfinance banks (MfBs) act as outlets through which the funds are released to service providers based on pre-determined milestones. A presidential task force on power (PTFP) is proposed to regulate and monitor the activities of the rural electrification agency (REA), NERC and the Ministry of Environment (MoENV) with relation to the deployment of SHSs. This taskforce is to ensure that compliance of the service providers to codes and guidelines that would be routinely issued from the collaboration between the NERC, MoENV and REA. Furthermore, the service providers are expected to communicate challenges to the PTFP and its cohorts (NERC, REA and MoENV). Funds are only released to the service providers based on approval from the PTFP. A key addition to this proposed model is the use of independent assessors (IA) and field support officers (FSO). While the independent assessors are meant to assess the performers of the deployed SHSs to the households vis-à-vis its contribution to the QoL of households and further assess the performance of the service providers to quickly resolving technical and other related problems as raised by the households, the field support officers are expected to liaise more frequently between the households and the service providers. As an interface, they are expected to provide support to the households by ensuring that every household is carried along.

The Table 28 shows the ability of the proposed classified SHSs to meet the electricity requirement of the various home classes while the Table 29 depicts the additional capacity (in 
terms of electrical appliance ownership) that houses need to acquire/drop to move between various SHSs. A strong argument for this classification of the SHSs system is to prevent wastage and indiscriminate usage of electricity by home owners a fact rightly observed in [56].

\section{Conclusion}

The importance of energy (electricity) has been explicitly shown to be a driver of any economy [57-59]. This work has addressed the energy (electricity) poverty in Nigeria by critically examining the generation, transmission and distribution of electricity. It has been shown that with current policies and existing infrastructure on ground, government is not poised to achieving much considering the low hourly electricity per capita for Nigerian's which has been shown to vary across the states in the country. Low grid connections in the northern states have been attributed to the high poverty index in the state and low economic activity in the northern region. This has further translated to low literacy levels and poor healthcare delivery. Rather than being conventional and addressing the problems of transmission and distribution, embedded generation is being proposed as a quick, efficient and viable approach to addressing the problem of energy (electricity) poverty. It has been shown that distributed generation technologies provide an avenue to tackle electricity per capita at regional levels rather than at the national levels and is also the best solution at fully exploiting renewable energy sources.

In improving electricity access to rural and off grid communities the critical role of government has been emphasized from creating an enabling environment to finance, policy and regulations. Private partnerships have also been seen to be indispensable as they exploit the prevailing energy crisis scenario turning it into business opportunities as have been done by the BUC, SPDC, and NAOC in Nigeria. The issues of grid code connections have been left out in this discussion as the export of electricity/grid interconnection of electricity from these proposed DGs to other communities is not envisioned for now considering that the exploitation in the short to medium term is targeting self-sufficiency and a zero import situation. However, existing transmission codes in Nigeria utilize the standard $11 \mathrm{kV}, 33 \mathrm{kV}, 132 \mathrm{kV}$ or $330 \mathrm{kV}$. Grid interconnection on a regional or national basis would thus further define the types of transformers that should be purchased and the nature of the transmission station that should be built considering line losses and conductor types. 
Furthermore, the role of solar home systems (SHSs) as palliatives to assuaging the impact of non-availability of electricity to most rural off grid communities has also been examined. In proposing SHSs roll out, a sustainable scheme that is also economically viable has been proposed. While the SHS is not meant to obviate the need for a more comprehensive solution to electrifying these communities, it is however meant to in the short term induce and stimulate economic development which is urgently needed to fast track diversification of the economy and nip the rising inflation and recession the Nigerian economy is currently experiencing. This is helpful for preserving the small scale businesses and empowering vulnerable business owners with means to remain afloat and cut down on the rising costs associated with sourcing electricity from alternative sources.

The Nigerian market portends enormous opportunities for the full utilization and integration of renewables. The declining oil prices and lowering imports of crude oil by oil dependent countries signal that countries are increasing their mix of RE in their overall energy base. It becomes imperative that government aggressively begins pushing policies that would see to the buildup of up to date technology in RE integration and local manufacturing of solar cells and solar water heaters. Tax rebates and exemption of RE components would go a long way in reducing the overall cost of purchase while government funding of all or most of the connection costs would encourage consumers to adopt RET. The government could also exploit the benefits of the feed in tariff (FiT) system being practiced in most developed countries and even in some African countries with a view to supporting electricity production from RE. The incorporation of carbon tax into the bills of existing grid based customers could also be an incentive to increase the patronage of RE. The peculiarity of the Nigerian market calls for a concerted and well mapped out plan considering the huge percentage of the country's population who are poor. The success of the BUC project in Bonny Island should be studied and used in rolling out comprehensive guidelines to govern the deployment of RE.

The strengthening of institutions tasked with delivering and regulating the deployment of RETs in the country like the rural electrification agency (REA), the energy commission of Nigeria (ECN), NERC etc. cannot be overemphasized. The employment of personnel to administer their affairs should be based purely on merit rather than the so-called federal character representation which has only bred incompetence. 
Lastly, these institutions tasked with the safe delivery of the objectives of the REMP should be immune to government change. Rather than having executives whose service is at the pleasure of the executive arm of government, personnel of these institutions should have their employment tenured and constitutionally backed up. This way they would not face repercussions occasioned by a change in government.

\section{Acknowledgements}

The financial assistance of the Shell Petroleum Development Company of Nigeria Limited (SPDC) and the National Research Foundation (NRF) towards this research is hereby acknowledged. Opinions expressed and conclusions arrived at, are those of the authors and are not necessarily to be attributed to the NRF. 


\section{References}

1. Fehrenbach, D., et al., On the economic potential for electric load management in the German residential heating sector: An optimising energy system model approach. Energy, 263-276, (2014). Energy, 2014. 71: p. 263-276.

2. Paleta, R., A. Pina, and C.A. Silva, Remote Autonomous Energy Systems Project: Towards sustainability in developing countries. Energy. 48(1): p. 431-439.

3. Sesan, T., Navigating the limitations of energy poverty: Lessons from the promotion of improved cooking technologies in Kenya. Energy Policy. 47: p. 202-210.

4. Kaygusuz, K., Energy for sustainable development: A case of developing countries. Renewable and Sustainable Energy Reviews. 16(2): p. 1116-1126.

5. Adaramola, M.S., Viability of grid-connected solar PV energy system in Jos, Nigeria. International Journal of Electrical Power \& Energy Systems. 61: p. 64-69.

6. Oseni, M.O., Improving householdsâ€ $\epsilon^{\mathrm{TM}}$ access to electricity and energy consumption pattern in Nigeria: Renewable energy alternative. Renewable and Sustainable Energy Reviews. 16(6): p. 3967-3974.

7. Mohammed, Y.S., M.W. Mustafa, and N. Bashir, Status of renewable energy consumption and developmental challenges in Sub-Sahara Africa. Renewable and Sustainable Energy Reviews. 27: p. 453-463.

8. Mohammed, Y.S., et al., Renewable energy resources for distributed power generation in Nigeria: A review of the potential. Renewable and Sustainable Energy Reviews. 22: p. 257-268.

9. Chakravarty, S. and M. Tavoni, Energy poverty alleviation and climate change mitigation: Is there a trade off? Energy Economics, 2013. 40: p. S67-S73.

10. Kanagawa, M. and T. Nakata, Analysis of the energy access improvement and its socioeconomic impacts in rural areas of developing countries. Ecological Economics, 2007. 62: p. 319-329.

11. Pachauri, S., et al., On Measuring Energy Poverty in Indian Households. World Development, 2004. 32: p. 2083-2104.

12. Spagnoletti, B. and T. O'Callaghan, Let there be light: A multi-actor approach to alleviating energy poverty in Asia. Energy Policy, 2013. 63: p. 738-746.

13. Ahlborg, H. and L. Hammar, Drivers and barriers to rural electrification in Tanzania and Mozambique $\hat{a} \epsilon$ " Grid-extension, off-grid, and renewable energy technologies. Renewable Energy. 61: p. 117-124.

14. Ohunakin, O.S., et al., Solar energy applications and development in Nigeria: Drivers and barriers. Renewable and Sustainable Energy Reviews. 32: p. 294-301.

15. Sovacool, B.K., et al., What moves and works: Broadening the consideration of energy poverty. Energy Policy. 42: p. 715-719.

16. Iyke, B.N., Electricity consumption and economic growth in Nigeria: A revisit of the energy-growth debate. Energy Economics. 51: p. 166-176.

17. Sovacool, B.K., Confronting energy poverty behind the bamboo curtain: A review of challenges and solutions for Myanmar (Burma). Energy for Sustainable Development, 2013. 17: p. 305-314.

18. Nigeria : Expanding Access to Rural Infrastructure Issues and Options for Rural Electrification, Water Supply and Telecommunications. 2005: Washington, DC.

19. Shaaban, M. and J.O. Petinrin, Renewable energy potentials in Nigeria: Meeting rural energy needs. Renewable and Sustainable Energy Reviews. 29: p. 72-84.

20. Ajayi, O.O., Assessment of utilization of wind energy resources in Nigeria. Energy Policy, 2009. 37(2): p. 750-753.

21. Ajayi, O.O. and O.O. Ajayi, Nigeria's energy policy: Inferences, analysis and legal ethics toward RE development. Energy Policy. 60: p. 61-67. 
22. Aliyu, A.S., A.T. Ramli, and M.A. Saleh, Nigeria electricity crisis: Power generation capacity expansion and environmental ramifications. Energy. 61: p. 354-367.

23. Chineke, T.C. and F.M. Ezike, Political will and collaboration for electric power reform through renewable energy in Africa. Energy Policy. 38(1): p. 678-684.

24. Gujba, H., Y. Mulugetta, and A. Azapagic, Power generation scenarios for Nigeria: An environmental and cost assessment. Energy Policy. 39(2): p. 968-980.

25. Oseni, M.O., An analysis of the power sector performance in Nigeria. Renewable and Sustainable Energy Reviews. 15(9): p. 4765-4774.

26. Suberu, M.Y., et al., Power sector renewable energy integration for expanding access to electricity in sub-Saharan Africa. Renewable and Sustainable Energy Reviews. 25: p. 630-642.

27. Thiam, D.R., An energy pricing scheme for the diffusion of decentralized renewable technology investment in developing countries. Energy Policy. 39(7): p. 4284-4297.

28. Welsch, M., et al., Smart and Just Grids for sub-Saharan Africa : Exploring options. Renewable and Sustainable Energy Reviews. 20: p. 336-352.

29. Dada, J.O., Towards understanding the benefits and challenges of Smart/Micro-Grid for electricity supply system in Nigeria. Renewable and Sustainable Energy Reviews. 38: p. 1003-1014.

30. Adaramola, M.S., et al., Performance evaluation of wind turbines for energy generation in Niger Delta, Nigeria. Sustainable Energy Technologies and Assessments. 6: p. 75-85.

31. Mohammed, Y.S., et al., Sustainable potential of bioenergy resources for distributed power generation development in Nigeria. Renewable and Sustainable Energy Reviews. 34: p. 361-370.

32. Ohunakin, O.S., et al., Solar radiation variability in Nigeria based on multiyear RegCM3 simulations. Renewable Energy. 74: p. 195-207.

33. Al-Ghandoor, A., et al., Electricity consumption and associated GHG emissions of the Jordanian industrial sector: Empirical analysis and future projection. Energy Policy, 2008. 36(1): p. 258-267.

34. Ahmed, S., et al., Exploitation of renewable energy for sustainable development and overcoming power crisis in Bangladesh. Renewable Energy. 72: p. 223-235.

35. Lo, K., A critical review of China's rapidly developing renewable energy and energy efficiency policies. Renewable and Sustainable Energy Reviews. 29: p. 508-516.

36. Nnaji, B., FEDERAL REPUBLIC OF NIGERIA POWER SECTOR OUTLOOK IN NIGERIA : Governments Renewed Priorities. June 2011: Securities and Exchange Commission.

37. Pestana, C., A. Ibiowie, and S. Managi, Nigeria $\hat{a} \epsilon^{\mathrm{TM}} s$ power sector : Analysis of productivity. Economic Analysis and Policy. 44(1): p. 65-73.

38. Oyedepo, S.O., On energy for sustainable development in Nigeria. Renewable and Sustainable Energy Reviews. 16(5): p. 2583-2598.

39. Giwa, A., et al., A comprehensive review on biomass and solar energy for sustainable energy generation in Nigeria. Renewable and Sustainable Energy Reviews. 69: p. 620641.

40. Aliyu, A.S., J.O. Dada, and I.K. Adam, Current status and future prospects of renewable energy in Nigeria. Renewable and Sustainable Energy Reviews. 48: p. 336-346.

41. Mohammed, Y.S., et al., Existing and recommended renewable and sustainable energy development in Nigeria based on autonomous energy and microgrid technologies. Renewable and Sustainable Energy Reviews.

42. Odiase, S. and C. Nwaoha, Improving Market Efficiency: Low Income Consumers and the Power Sector Reforms. 2015, NIAF: Abuja.

43. Ifeanyi-Nwaoha, C. and B. Sajou, Embedding the Power Sector Reform through the National Customer Enumeration Exercise. 2016, NIAF: Abuja. 
44. Fadare, D.A., Modelling of solar energy potential in Nigeria using an artificial neural network model. Applied Energy, 2009. 86(9): p. 1410-1422.

45. Cloutier, M. and P. Rowley, The feasibility of renewable energy sources for pumping clean water in sub-Saharan Africa: A case study for Central Nigeria. Renewable Energy. 36(8): p. 2220-2226.

46. Abubakar S, S. The place of renewable energy in the Nigerian energy sector. in World Future Council Workshop on Renewable Energy Policies. 2009. Addis, Ababa.

47. Sambo, A.S. The place of renewable energy in the Nigerian energy sector. in world future council workshop on renewable energy policies. 2009. Addis Ababa, Ethiopia.

48. T. R. Ayodele and A.S.O. Ogunjuyigbe, Increasing household solar energy penetration through load partitioning based on quality of life: The case study of Nigeria. Sustainable Cities and Society, 2015. 18: p. 21-31.

49. IEA, Deploying renewables in Southeast Asia: Trends and potentials. 2010.

50. IEA, Integration of renewables: status and challenges in China. 2011.

51. FGN, Nigeria Industrial Revolution Plan. 2014, Federal Ministry of Industry Trade Investment.

52. IFC, From Gap to Opportunity: Business models for scaling up energy access. 2012, World Bank Group.

53. IFC, Lighting Africa Market Trends Report: Overview of the off-grid lighting market in Africa in Lighting Africa. 2012, World Bank Group.

54. ERSU;, PMU; and TCN, Nigeria Electricity Transmission Project (NETAP) Environmental and Social Management Framework (ESMF). 2016.

55. GPOBA, Improving Rural Electricity Access through Solar Home Systems in Ghana. 2016.

56. Monyei, C.G., B. Chong, and A.O. Adewumi. An integrated dynamic pricing scheme for improving the smartness of off grid distributed generation. in 2016 IEEE Power and Energy Conference at Illinois (PECI).

57. Groh, S., The role of energy in development processesâ€'The energy poverty penalty: Case study of Arequipa (Peru). Energy for Sustainable Development. 18: p. 83-99.

58. Silva Herran, D. and T. Nakata, Design of decentralized energy systems for rural electrification in developing countries considering regional disparity. Applied Energy. 91(1): p. 130-145.

59. Sovacool, B.K., The political economy of energy poverty: A review of key challenges. Energy for Sustainable Development. 16(3): p. 272-282. 


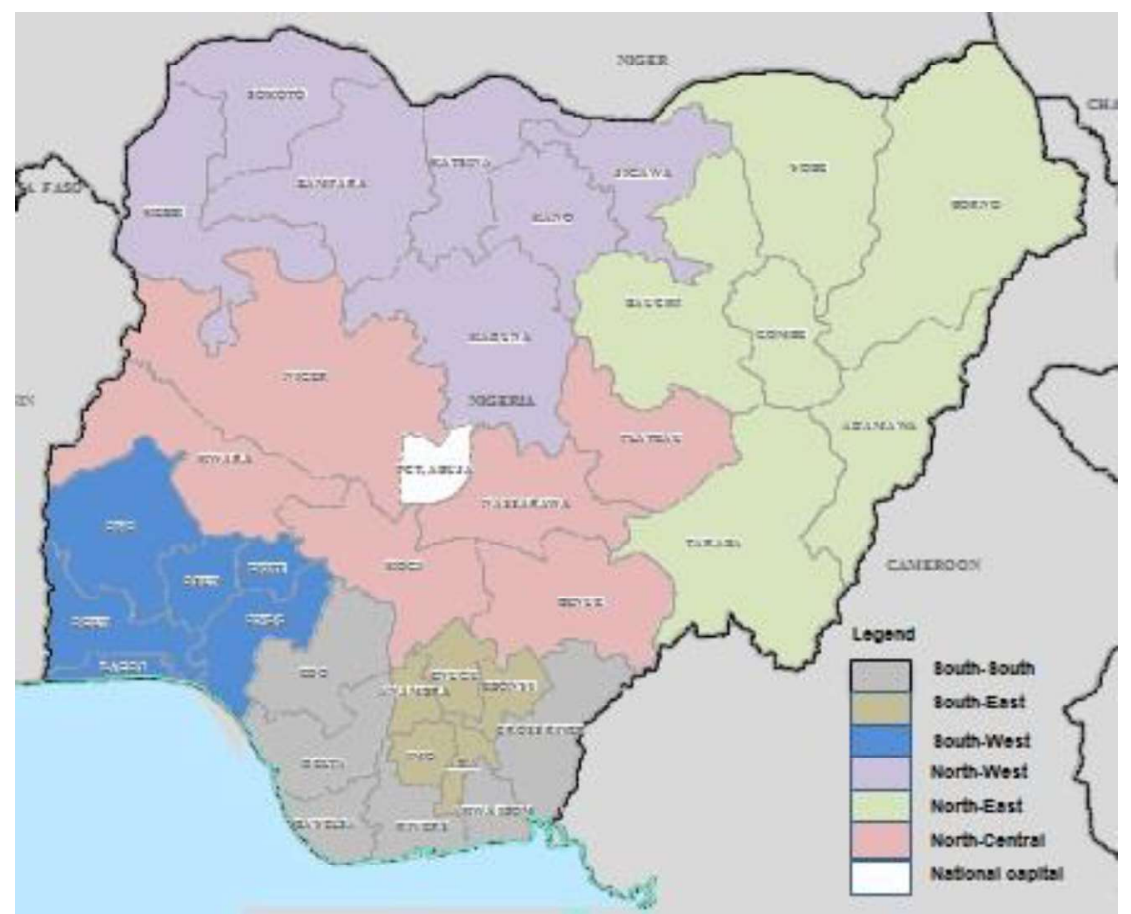

Figure 1: Nigeria's geo-political zones and the FCT

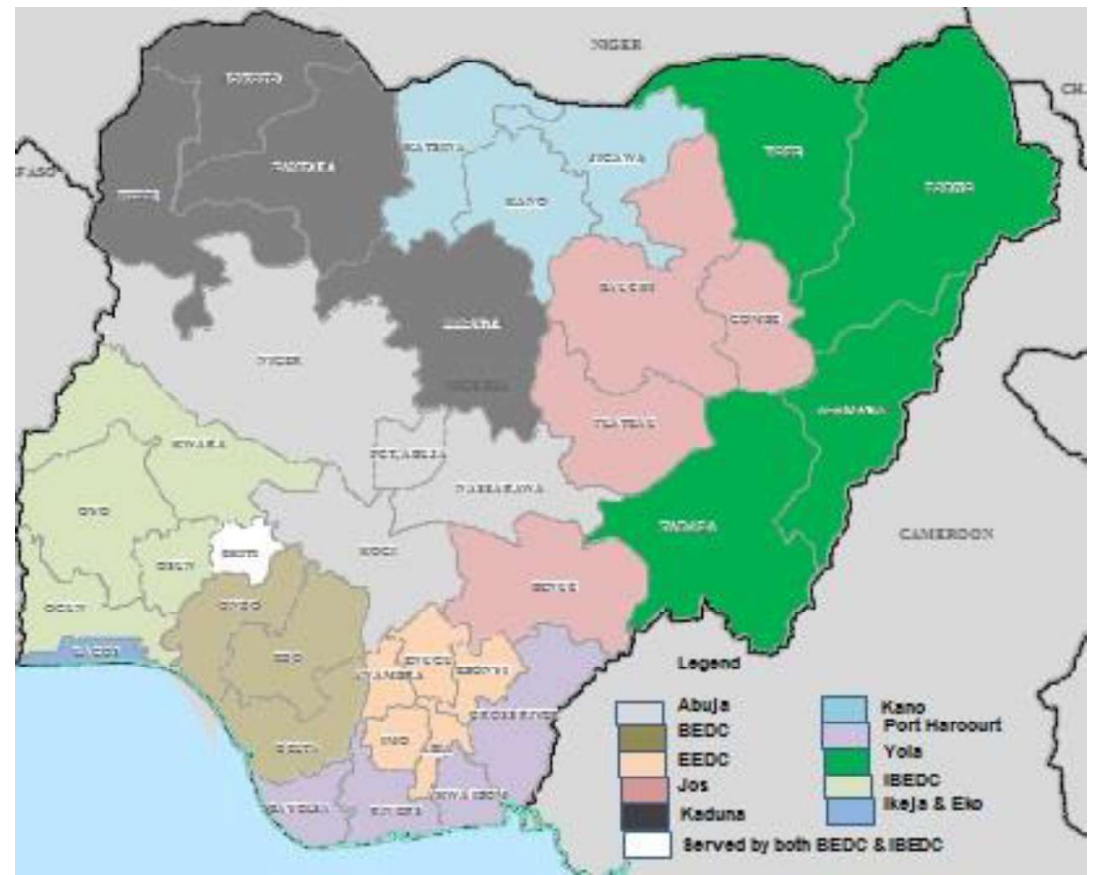

Figure 2: DISCO's and their coverage areas 


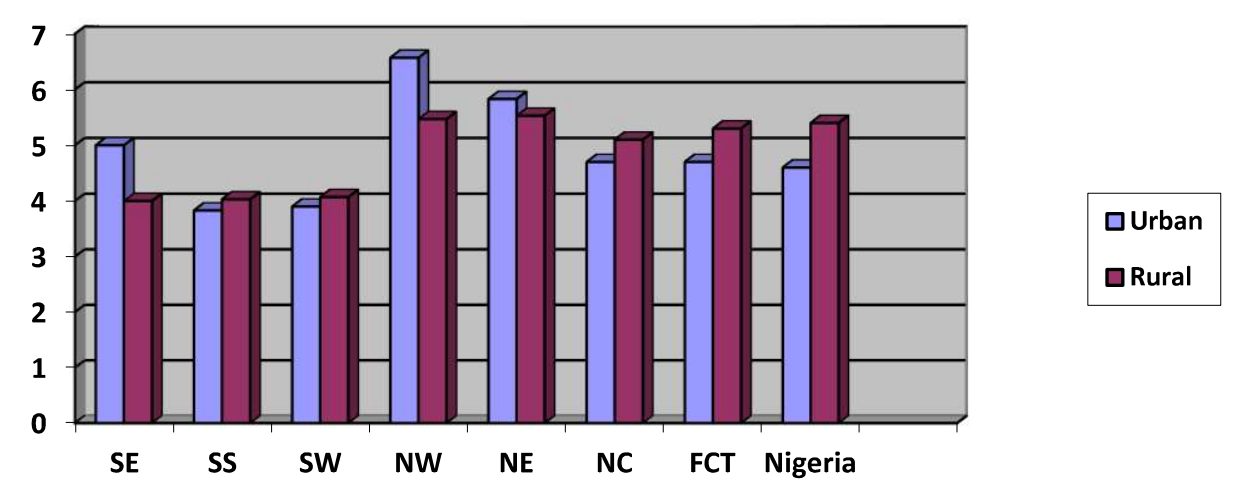

Figure 3: Urban and rural average household size for geo-political zones, FCT and Nigeria

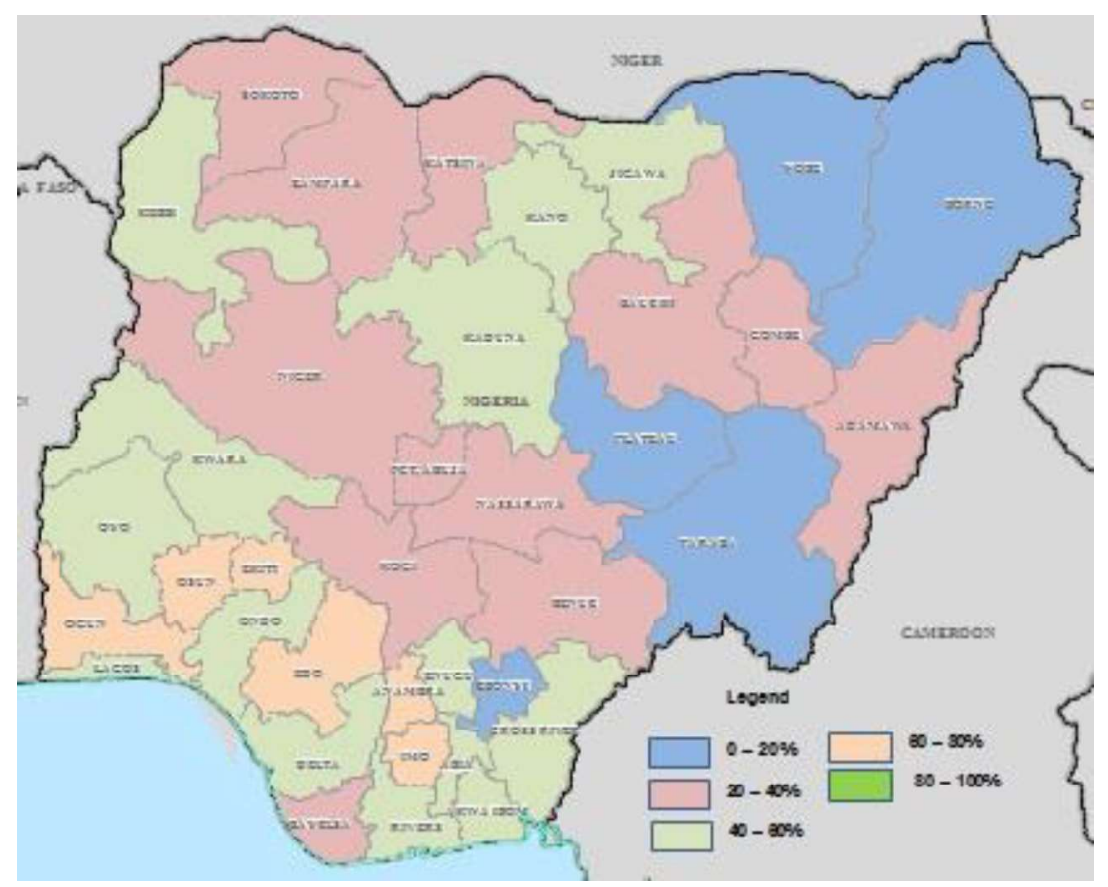

Figure 4: Grid connection of states' households (\%) 


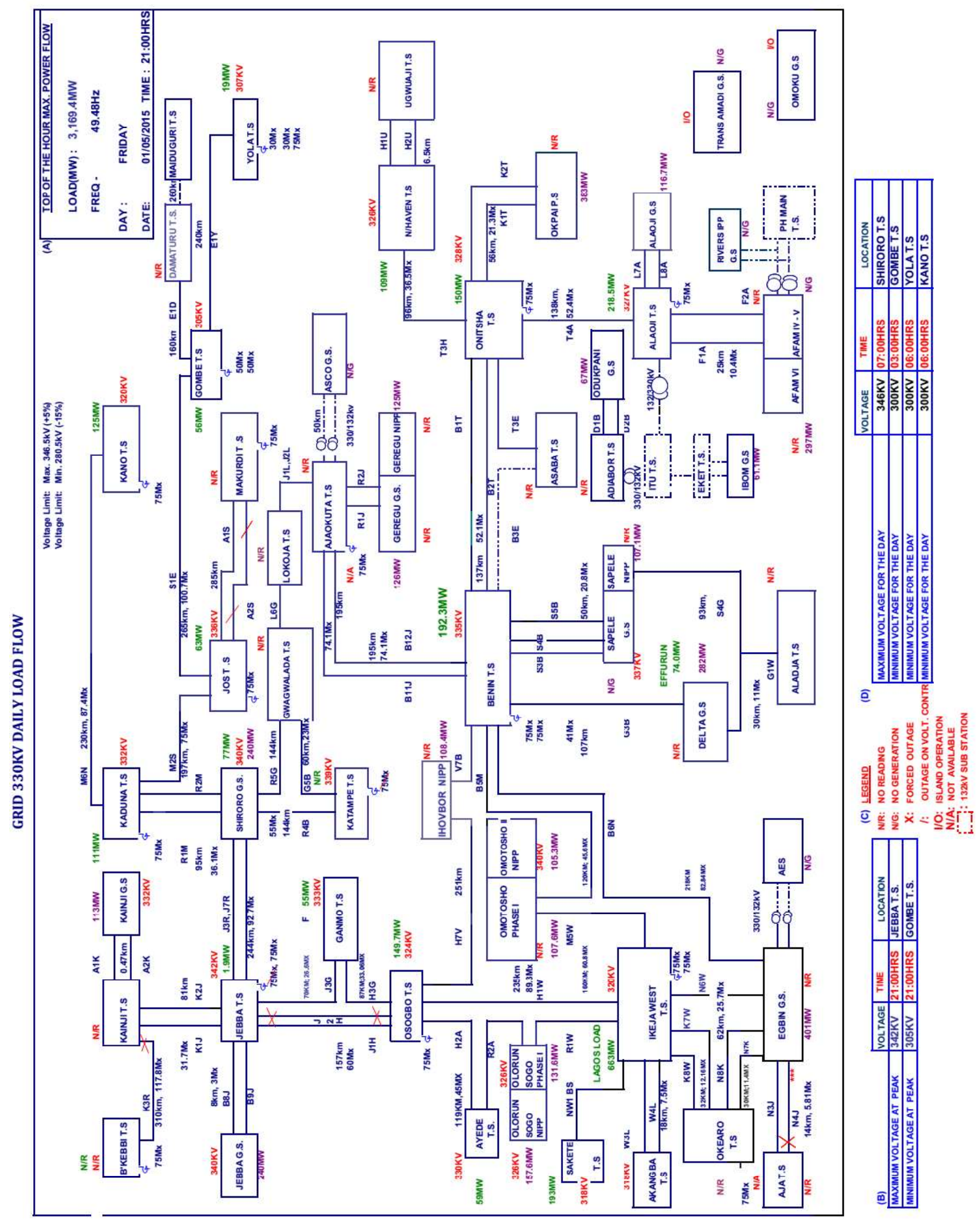

Figure 5: The Nigeria $330 \mathrm{kV}$ grid load flow for 01/05/2015 at 21:00 hrs. (source: National Control Centre, Osogbo) 


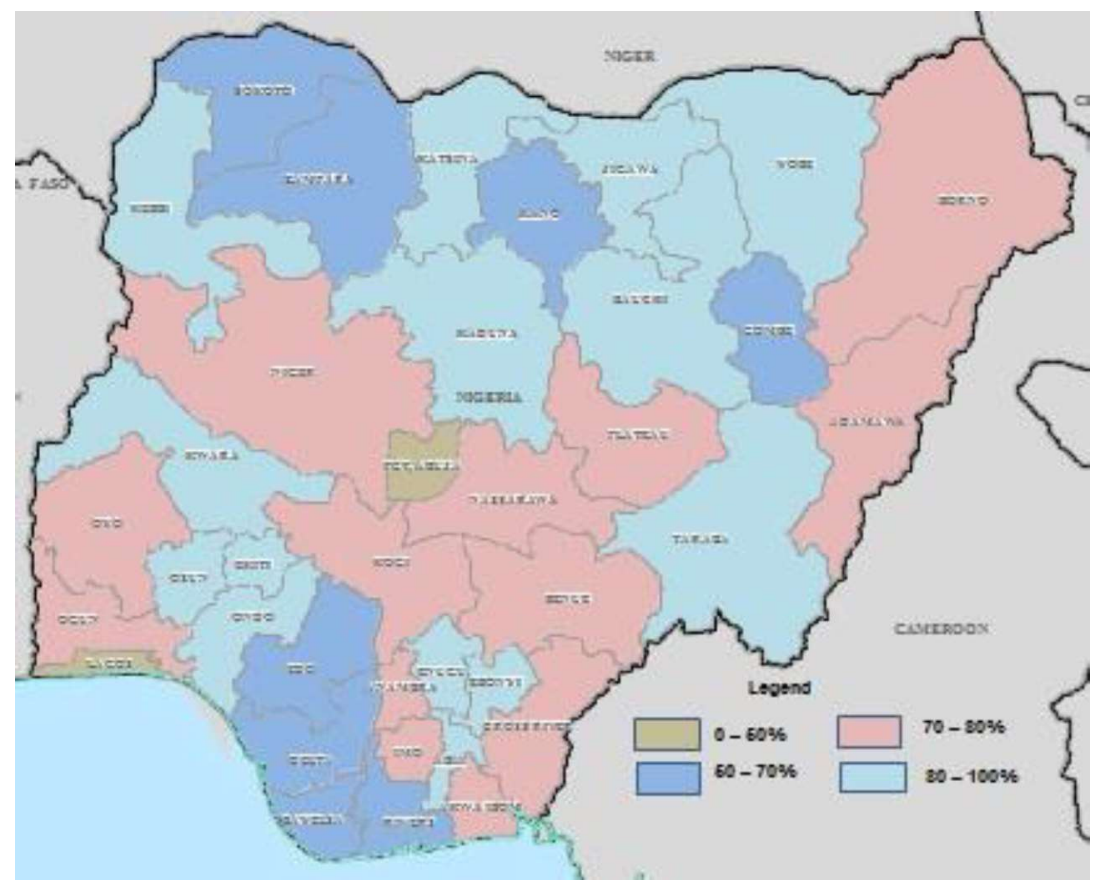

Figure 6: Poverty distribution in Nigerian households by state

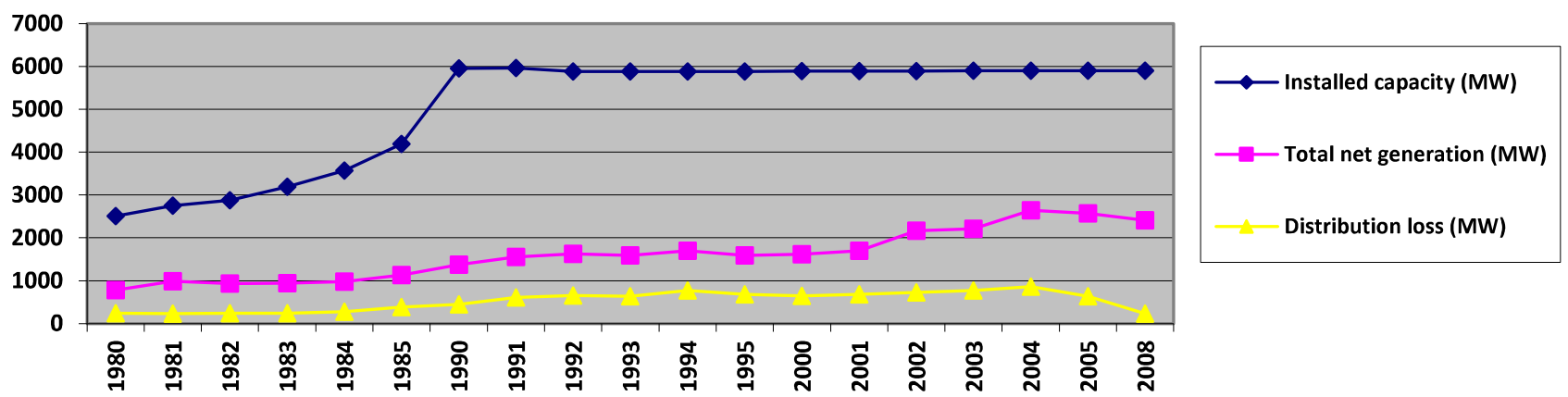

Figure 7: Comparison plot between installed capacity, net generation and distribution losses (MW) for selected years 


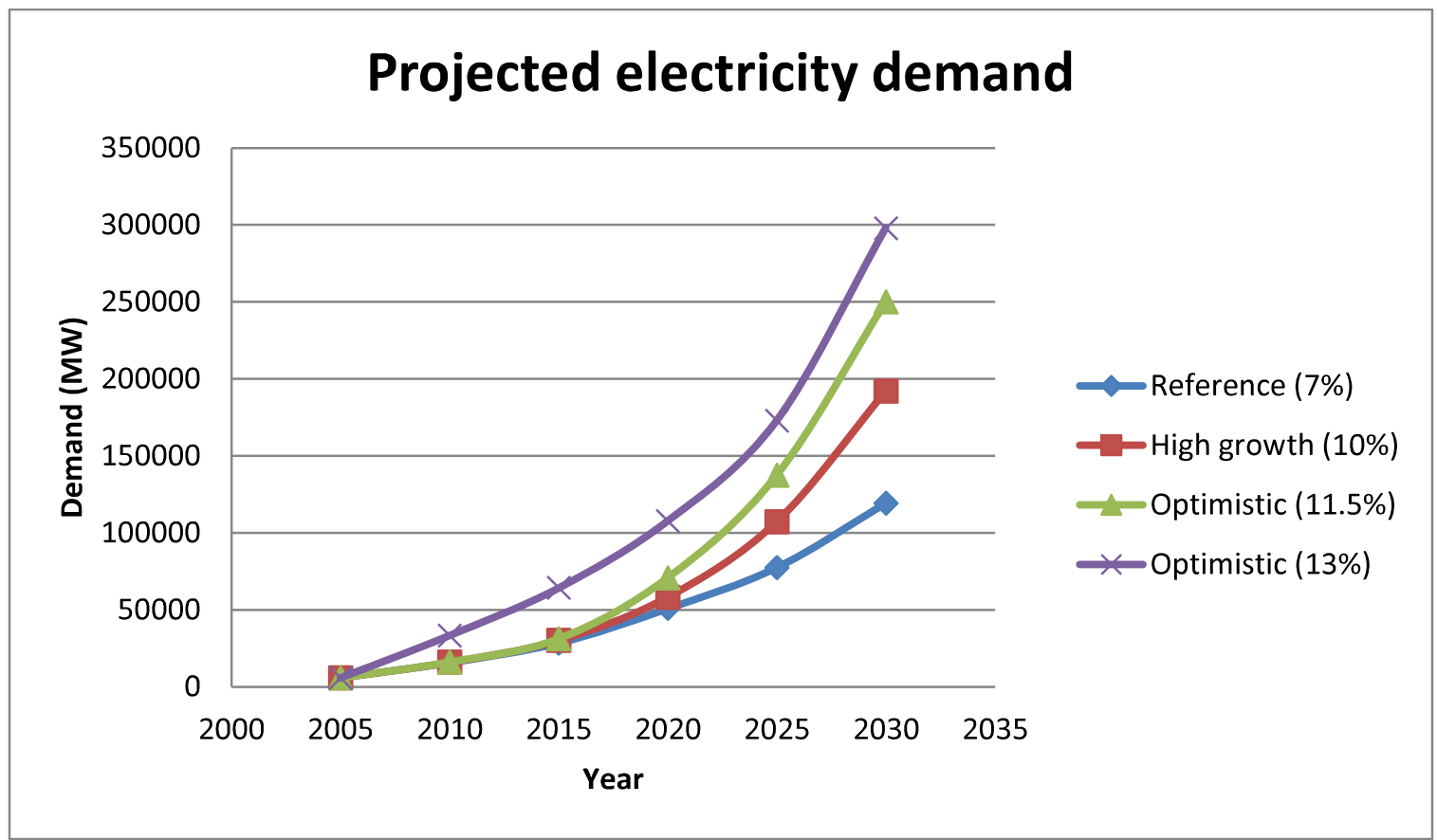

Figure 8: projected electricity demand

\section{Household energy use profile for urban areas}

(\%)

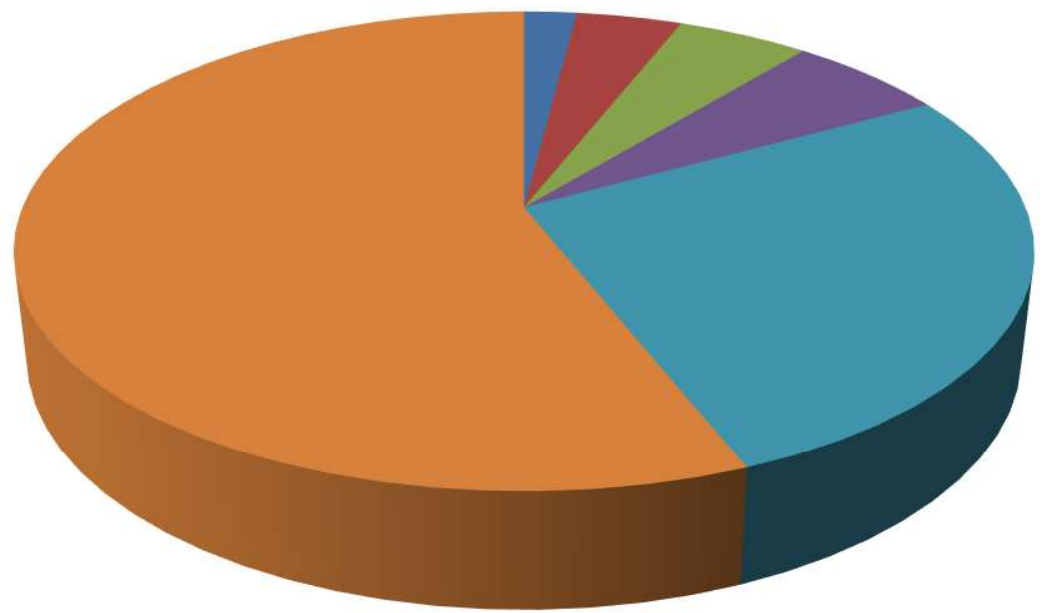

- Sawdust

Electricity

- Gas

- Charcoal

Kerosene

Firewood

Figure 9: Household energy use profile for urban areas 


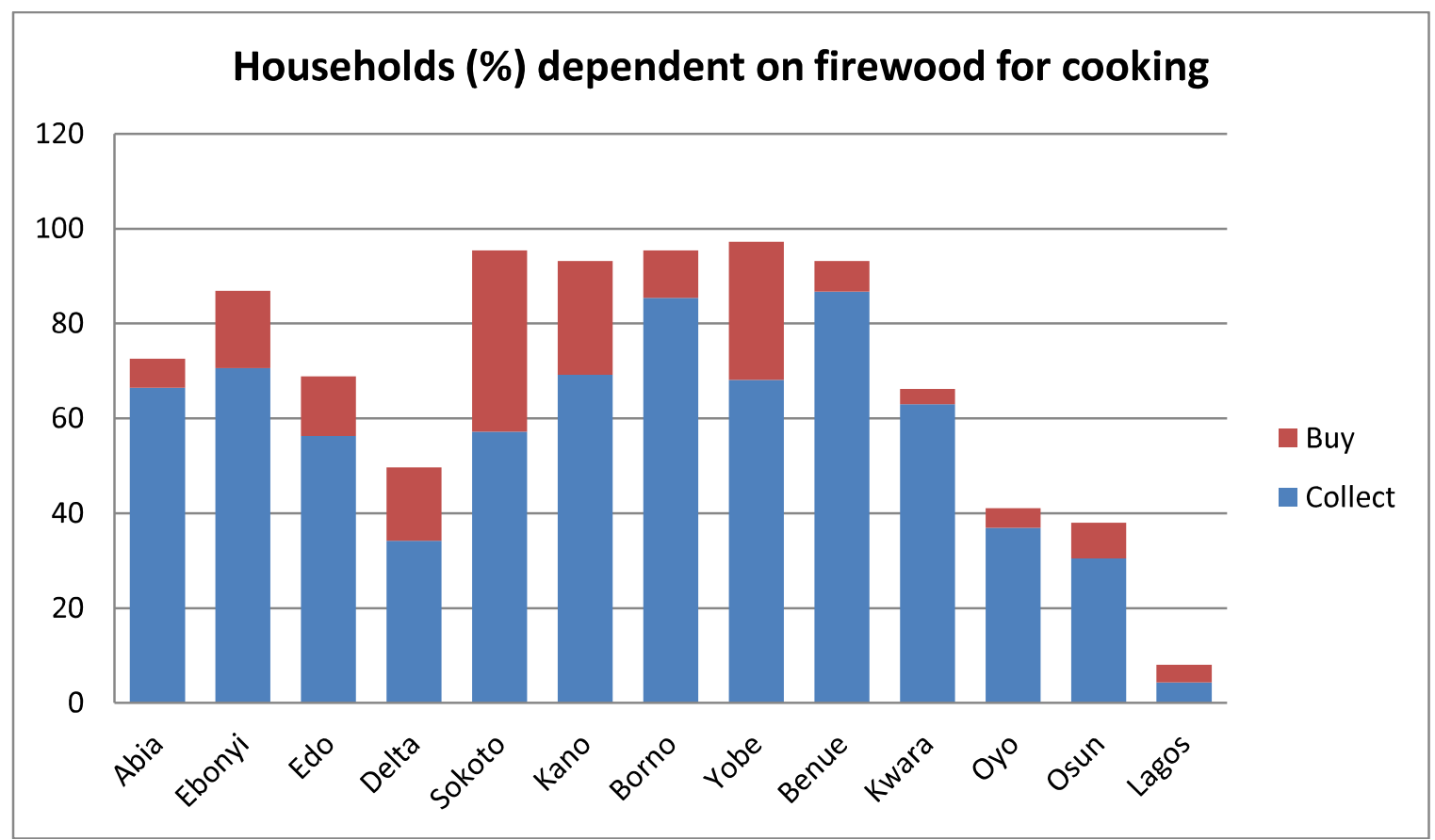

Figure 10: Households dependency on firewood for cooking

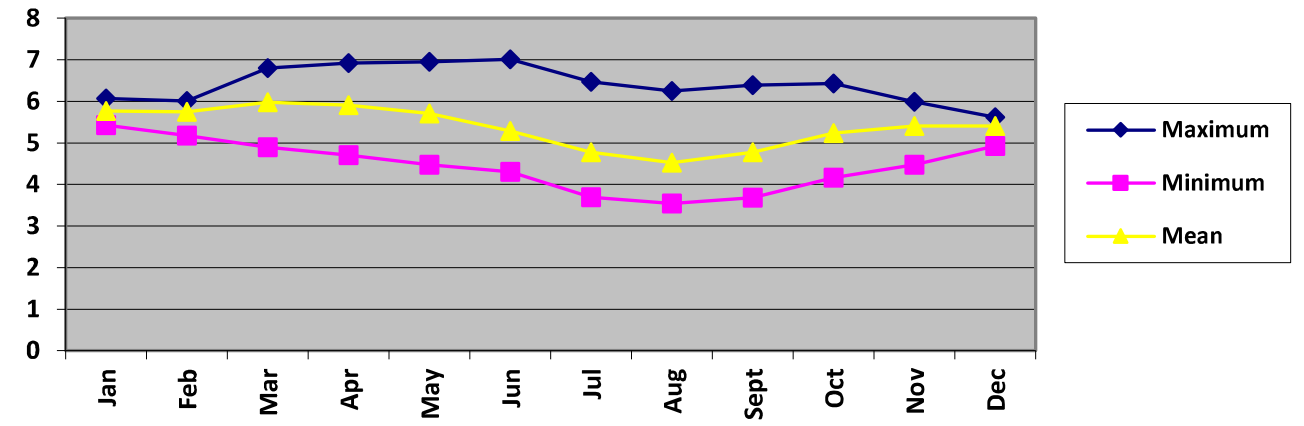

Figure 11: Maximum, minimum and mean yearly solar potential variation in Nigeria 


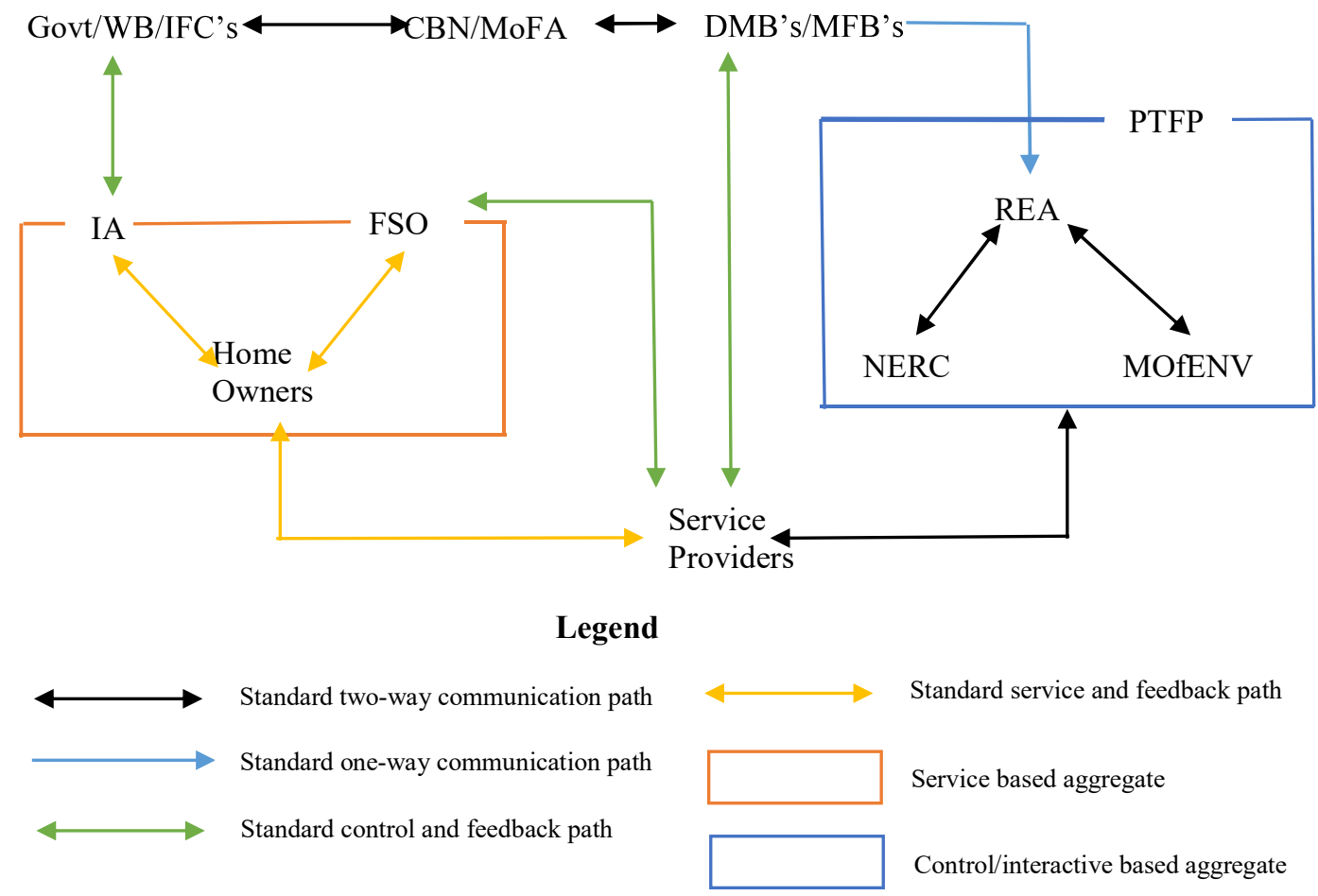

Figure 12: Proposed sustainable and economically viable SHS roll out scheme 
Table 1: Some basic facts about Nigeria

\begin{tabular}{|c|c|c|c|c|c|c|}
\hline \multicolumn{5}{|c|}{ Basic facts about Nigeria } & & \\
\hline \multicolumn{3}{|c|}{ Population } & \multicolumn{2}{|c|}{$140,431,790^{*}$} & & \\
\hline \multicolumn{3}{|c|}{ Male (\% of population) } & \multicolumn{2}{|c|}{$51.40^{\#}$} & & \\
\hline \multicolumn{3}{|c|}{ Female ( $\%$ of population) } & \multicolumn{2}{|l|}{$48.60^{\#}$} & & \\
\hline \multicolumn{7}{|c|}{ Sector } \\
\hline \multicolumn{3}{|c|}{ Urban population (\% of total population) } & \multicolumn{2}{|l|}{$50.80 * *$} & & \\
\hline \multicolumn{3}{|c|}{ Rural population (\% of total population) } & \multicolumn{2}{|l|}{$49.20 * *$} & & \\
\hline \multicolumn{3}{|c|}{ Number of states } & \multicolumn{2}{|l|}{$36^{*}$} & & \\
\hline \multicolumn{3}{|c|}{ Number of local governments } & \multicolumn{2}{|c|}{$774 *$} & & \\
\hline \multicolumn{3}{|c|}{ Land size } & \multicolumn{2}{|c|}{$923,768 \mathrm{~km}^{2 *}$} & & \\
\hline \multicolumn{3}{|c|}{ GDP per capita (constant 2005 US\$) } & \multicolumn{2}{|c|}{$1097.97 * *$} & & \\
\hline \multicolumn{7}{|c|}{$*($ see ref $[33]) \quad * *(2013$ World Bank est. $)$} \\
\hline \multicolumn{7}{|c|}{ \# (Source: NBS/CBN/NCC Socio-economic survey on Nigeria, 2008) } \\
\hline \multirow[t]{2}{*}{ Geo-political zones } & South East & South-South & South West & North West & North East & North Central \\
\hline & Abia & Edo & Oyo & Sokoto & Borno & Benue \\
\hline \multirow[t]{3}{*}{ States } & Ebonyi & Delta & Osun & Kano & Yobe & Kwara \\
\hline & Imo & Rivers & Lagos & Zamfara & Gombe & Niger \\
\hline & & & & & & $\mathrm{FCT}$ \\
\hline
\end{tabular}

Table 3: Geo-political zones average household size

\begin{tabular}{lllllll}
\hline Geo-political zones & South East & South-South & South-West & North West & North East & North Central \\
\hline & Abia & Edo & Oyo & Sokoto & Borno & Benue \\
\hline Urban & 4.0 & 3.6 & 4.1 & 6.6 & 4.6 & 5.0 \\
Rural & 3.7 & 4.0 & 3.9 & 4.7 & 5.4 & 6.4 \\
\hline & Ebonyi & Delta & Osun & Kano & Yobe & Kwara \\
\hline Urban & 5.4 & 4.1 & 3.8 & 7.2 & 6.2 & 4.5 \\
Rural & 3.9 & 3.5 & 4.1 & 6.3 & 5.4 & 4.0 \\
\hline & Imo & Rivers & Lagos & Zamfara & Gombe & Niger \\
\hline Urban & 5.6 & 3.8 & 3.8 & 5.9 & 6.7 & 4.6 \\
Rural & 4.4 & 4.6 & 4.2 & 5.4 & 5.8 & 4.9 \\
\hline
\end{tabular}

Source: NBS/CBN/NCC Socio-economic survey on Nigeria, 2008

Table 4: Nigeria and FCT average household size

\begin{tabular}{lll}
\hline & Nigeria & FCT \\
\hline Urban & 4.6 & 4.7 \\
Rural & 5.4 & 5.3 \\
\hline
\end{tabular}

Source: NBS/CBN/NCC Socio-economic survey on Nigeria, 2008

Table 5: Electricity supply by source for representative states (\%)

\begin{tabular}{llllllll}
\hline & PHCN only & RE only & PG only & PHCN/PG & RE/PG & Solar panel & none \\
\hline Abia & 45.7 & 1.3 & 6.5 & 13.5 & 1.8 & 31.1 \\
Ebonyi & 12.3 & 8.3 & 3.2 & 2.5 & 5.6 & 68.1 \\
Imo & 69.5 & 0.3 & 4.6 & 12.8 & 0.2 & 12.6
\end{tabular}




\begin{tabular}{|c|c|c|c|c|c|c|c|}
\hline Edo & 77.7 & 1.9 & 2.0 & 3.2 & & & 15.2 \\
\hline Delta & 56.8 & & 2.9 & 7.5 & 3.1 & & 29.6 \\
\hline Rivers & 41.0 & 0.7 & 13.8 & 11.9 & 10.9 & & 21.7 \\
\hline Oyo & 47.5 & & 5.3 & 8.2 & 0.2 & & 38.8 \\
\hline Osun & 63.6 & & 1.2 & 1.4 & & & 33.9 \\
\hline Lagos & 57.0 & & 0.9 & 40.9 & 0.9 & & 0.3 \\
\hline Sokoto & 29.8 & & 0.2 & 0.3 & 0.2 & & 69.5 \\
\hline Kano & 42.6 & & 0.3 & 0.8 & & & 56.2 \\
\hline Zamfara & 21.5 & 0.2 & 0.2 & 0.5 & & 0.5 & 77.1 \\
\hline Borno & 15.2 & & 3.8 & 3.6 & & 0.2 & 77.3 \\
\hline Yobe & 18.1 & 0.7 & 0.7 & 2.1 & 0.4 & & 78.0 \\
\hline Gombe & 39.5 & 0.9 & 0.9 & 3.4 & & & 55.4 \\
\hline Benue & 22.8 & & 4.2 & 0.9 & 0.2 & & 72.0 \\
\hline Kwara & 56.4 & & 1.5 & 3.6 & & & 38.5 \\
\hline Niger & 35.6 & & 6.2 & 1.6 & & & 56.6 \\
\hline
\end{tabular}

Source: NBS/CBN/NCC Socio-economic survey on Nigeria, 2008

RE: Rural electrification; PG: Private generator

Table 6: FGN and IPPs generation projections for 2013 - 2020

\begin{tabular}{|c|c|c|c|c|c|c|c|c|c|}
\hline \multirow[b]{2}{*}{ Category } & \multirow[b]{2}{*}{ Plant } & \multirow[b]{2}{*}{2013} & \multicolumn{7}{|c|}{ Capacity additions (MW) } \\
\hline & & & 2014 & 2015 & 2016 & 2017 & 2018 & 2019 & 2020 \\
\hline & Egbin & 1200 & & & & & & & \\
\hline & Afam IV \& V & 65 & & 276 & & & & & \\
\hline & Sapele Steam+Gas & 160 & & 300 & & & & & \\
\hline & Delta & 360 & & 200 & & & & & \\
\hline & Geregu & 410 & & & & & & & \\
\hline & Omotosho & 150 & 90 & & & & & & \\
\hline FGN & Olorunsogo & 180 & & & & & & & \\
\hline \multirow[t]{13}{*}{ GenCos } & Kaduna & & 200 & & & & & & \\
\hline & Shiroro & 600 & & & & & & & \\
\hline & Jebba & 450 & & & 90 & & & & \\
\hline & Kainji & 220 & & 220 & & & & & \\
\hline & Zuregu & & & & & & 350 & 350 & \\
\hline & Mambilla & & & & & & & 1300 & 1300 \\
\hline & Gurara & & 30 & & & & & & \\
\hline & Alaoji & 225 & 225 & & & & & & \\
\hline & Olorunsogo & 450 & 225 & & & & & & \\
\hline & Sapele & 450 & & & & & & & \\
\hline & Ihovbor & 450 & & & & & & & \\
\hline & Calabar & 112.5 & 450 & & & & & & \\
\hline & Gbarain & 112.5 & 112.5 & & & & & & \\
\hline \multirow[t]{4}{*}{ IPPs } & Geregu phase II & 434 & & & & & & & \\
\hline & Omotosho phase II & 450 & & & & & & & \\
\hline & Egbema & 112.5 & 225 & & & & & & \\
\hline & Omoku & 112.5 & 112.5 & & & & & & \\
\hline
\end{tabular}

Table 7: Targeted RE contribution to electricity generation in Nigeria

\begin{tabular}{llll}
\hline Resource & Short (MW) & Medium (MW) & Long (MW) \\
\hline Hydro (large) & 1,930 & 5,930 & 48,000 \\
Hydro (small) & 100 & 734 & 19,000 \\
Solar PV & 5 & 120 & 500 \\
Solar Thermal & - & 1 & 5 \\
Biomass & - & 100 & 800
\end{tabular}




\begin{tabular}{llll} 
Wind & 1 & 20 & 40 \\
\hline All renewables & 2,036 & 6,905 & 68,345 \\
All energy resources & 16,000 & 30,000 & 192,000 \\
$\%$ of renewables & $13 \%$ & $23 \%$ & $36 \%$ \\
\hline
\end{tabular}

Table 8: DisCos Percentage Load Allocation based on MYTO II

\begin{tabular}{|c|c|c|c|}
\hline \multicolumn{2}{|c|}{$\mathrm{S} / \mathrm{N} \quad$ DisCo } & \multirow{2}{*}{$\begin{array}{l}\text { Area } \\
\text { KATAMPE (ABUJA COMPLEX) } \\
\text { SHIRORO } \\
\text { TEGINA } \\
\text { AJAOKUTA }\end{array}$} & \multirow{2}{*}{$\begin{array}{l}\text { MYTO II Agreed percentage } \\
\text { load allocation } \\
11.5 \%\end{array}$} \\
\hline 1 & ABUJA & & \\
\hline 2 & IBADAN & $\begin{array}{l}\text { OSOGBO } \\
\text { OTTA } \\
\text { PAPALANTO } \\
\text { GANMO } \\
\text { AYEDE } \\
\text { ABEOKUTA } \\
\end{array}$ & $13.0 \%$ \\
\hline 3 & KANO & $\begin{array}{l}\text { KANO 2(KUMBOTSO, DAKATA 132/33KV) } \\
\text { KANO 1 (DAN-AGUNDI, HADEJIA, DUTSE/ AZARE, } \\
\text { KANKIA/KATSINA, KUMBOTSO, DAKATA 132/33KV) } \\
\text { KANO INTERNATIONAL AIRPORT }\end{array}$ & $8.0 \%$ \\
\hline 4 & YOLA & $\begin{array}{l}\text { YOLA } \\
\text { MAIDUGURI } 1 \\
\text { MAIDUGURI } 2\end{array}$ & $3.5 \%$ \\
\hline 5 & KADUNA & $\begin{array}{l}\text { BIRNIN-KEBBI (INCLUDING SOKOTO \& TALATA- } \\
\text { MAFARA) } \\
\text { KADUNA (1): KADUNA TOWN/ZARIA } \\
\text { KADUNA (2): FUNTUA-GUSAU }\end{array}$ & $8.0 \%$ \\
\hline 6 & BENIN & $\begin{array}{l}\text { BENIN } 1 \text { (IRRUA, UGHELLI, EFFURUN AND AMUKPE) } \\
\text { BENIN } 2\end{array}$ & $9.0 \%$ \\
\hline 7 & JOS & $\begin{array}{l}\text { JOS } \\
\text { GOMBE }\end{array}$ & $5.5 \%$ \\
\hline 8 & EKO & LAGOS- 1 (AJA; AKANGBA) & $11.0 \%$ \\
\hline 9 & ENUGU & $\begin{array}{l}\text { ALAOJI } \\
\text { ONITSHA } \\
\text { NEW HAVEN } \\
\end{array}$ & $9.0 \%$ \\
\hline 10 & 1KEJA & LAGOS- 2 (IKEJA WEST \& EGBIN AREA) & $15.0 \%$ \\
\hline 11 & $\begin{array}{c}\text { PORT } \\
\text { HARCOURT }\end{array}$ & $\begin{array}{l}\text { CALABAR } \\
\text { PORT HARCOURT } \\
\text { UYO-ITU-EKET }\end{array}$ & $6.5 \%$ \\
\hline SUI & TOTAL & & $100.0 \%$ \\
\hline
\end{tabular}

Table 9: Nigeria grid interruption from January 1998 to December 2004

\begin{tabular}{llllllll}
\hline Year & 1998 & 1999 & 2000 & 2001 & 2002 & 2003 & 2004 \\
\hline Number & 18 & 9 & 11 & 16 & 24 & 13 & 14 \\
\hline
\end{tabular}


Table 10: Poverty level in Nigeria for selected years

\begin{tabular}{llll}
\hline Year & Estimated population (million) & Population in poverty (million) & Poverty incidence (\%) \\
\hline 1980 & 65.0 & 17.1 & 27.2 \\
1985 & 75.0 & 34.7 & 41.3 \\
1992 & 91.5 & 39.2 & 42.7 \\
1996 & 102.3 & 67.1 & 65.6 \\
2004 & 126.3 & 68.7 & 54.4 \\
2010 & 163 & 112.47 & 69.0 \\
\hline
\end{tabular}

Table 11: Total energy (MWh) supplied DISCOs for 2007 and 2008

\begin{tabular}{llll}
\hline DISCO zone & $\begin{array}{l}\text { DISCO zone* } \\
\text { population }\end{array}$ & $\begin{array}{l}\text { 2007 total annual } \\
\text { energy supplied } \\
\text { DISCO's (MWh) }\end{array}$ & $\begin{array}{l}\text { 2008 total annual } \\
\text { energy supplied } \\
\text { DISCO's (MWh) }\end{array}$ \\
\hline Abuja & 10544431 & 2046158.75 & 2062328.62 \\
Lagos $^{*}$ & 9113605 & $4953137.75^{*}$ & $4412546.03^{*}$ \\
EEDC & 16431555 & 1931482.53 & 1816756.21 \\
Jos & 14448278 & 976667.61 & 835470.28 \\
Kaduna & 16351593 & 1650280.73 & 1417426.26 \\
Kano & 19563874 & 1002650.29 & 1065186.16 \\
Port Harcourt & 13698270 & 972504.31 & 908225.93 \\
Yola & 11966193 & 423504.31 & 375132.8 \\
BEDC & $10806688^{\#}$ & 2123766.27 & 2054046.9 \\
IBEDC & $15114346^{\#}$ & 2271074.42 & 2164011.78 \\
\hline
\end{tabular}

* (served by Eko and Ikeja) **(computed by summing member states population)

\# (computed by excluding Ekiti State)

Table 12: Yearly and monthly per capita electricity consumption

\begin{tabular}{lllll}
\hline & $\begin{array}{l}\text { Yearly Per capita } \\
\text { electricity } \\
\text { consumption } \\
\text { (kWh) for 2007 }\end{array}$ & $\begin{array}{l}\text { Yearly Per capita } \\
\text { electricity } \\
\text { consumption } \\
\text { (kWh) for 2008 }\end{array}$ & $\begin{array}{l}\text { Monthly Per capita } \\
\text { electricity } \\
\text { consumption } \\
\text { (kWh) for 2007 }\end{array}$ & $\begin{array}{l}\text { Monthly Per capita } \\
\text { electricity } \\
\text { consumption } \\
\text { (kWh) for 2008 }\end{array}$ \\
\hline Abuja & 194.0511 & 195.5846 & 16.1709 & 16.2987 \\
Lagos* & 543.4883 & 484.1713 & 45.2907 & 40.3476 \\
EEDC & 117.5472 & 110.5651 & 9.7956 & 9.21376 \\
Jos & 67.5975 & 57.8249 & 5.6331 & 4.8187 \\
Kaduna & 100.9248 & 86.6843 & 8.4104 & 7.2237 \\
Kano & 51.2501 & 54.4466 & 4.2708 & 4.5372 \\
Port Harcourt & 70.9947 & 66.3022 & 5.9162 & 5.5252 \\
Yola & 35.3917 & 31.3494 & 2.9493 & 2.6124 \\
BEDC & $196.5233^{\#}$ & 190.0718 & 16.3769 & 15.8393 \\
IBEDC & $150.2595^{\#}$ & 143.176 & 12.5216 & 11.9313 \\
\hline
\end{tabular}

*(served by Eko and Ikeja) \#(computed by excluding Ekiti State) 
Table 13: Daily and hourly per capita electricity consumption

\begin{tabular}{lllll}
\hline Disco zone & $\begin{array}{l}\text { Daily Per capita } \\
\text { electricity } \\
\text { consumption } \\
\text { (kWh) for 2007 }\end{array}$ & $\begin{array}{l}\text { Daily Per capita } \\
\text { electricity } \\
\text { consumption } \\
\text { (kWh) for 2008 }\end{array}$ & $\begin{array}{l}\text { Hourly Per capita } \\
\text { electricity } \\
\text { consumption } \\
\text { (Wh) for 2007 }\end{array}$ & $\begin{array}{l}\text { Hourly Per } \\
\text { capita electricity } \\
\text { consumption } \\
\text { (Wh) for 2008 }\end{array}$ \\
\hline Abuja & 0.5390 & 0.5433 & 22.4596 & 22.6371 \\
Lagos* & 1.5097 & 1.3449 & 62.9037 & 56.0383 \\
EEDC & 0.3265 & 0.3071 & 13.6050 & 12.7969 \\
Jos & 0.1878 & 0.1606 & 7.8238 & 6.6927 \\
Kaduna & 0.2803 & 0.2408 & 11.6811 & 10.0329 \\
Kano & 0.1424 & 0.1512 & 5.9317 & 6.3017 \\
Port Harcourt & 0.1972 & 0.1842 & 8.2170 & 7.6739 \\
Yola & 0.0983 & 0.0871 & 4.0963 & 3.6284 \\
BEDC & 0.5459 & 0.5280 & 22.7460 & 21.9990 \\
IBEDC & 0.4174 & 0.3977 & 17.3910 & 16.5710 \\
\hline *(served by Eko & and &
\end{tabular}

*(served by Eko and Ikeja) \#(computed by excluding Ekiti State)

Table 14: Households access by percentage

\begin{tabular}{lllll}
\hline States & Radio (\%) & Television (\%) & Mobile phone (\%) & PC (\%) \\
\hline Abia & 90.8 & 71.9 & 95.8 & 13.4 \\
Ebonyi & 93.6 & 35.0 & 81.8 & 5.1 \\
Imo & 93.8 & 80.9 & 97.3 & 5.6 \\
Edo & 97.1 & 88.8 & 96.8 & 8.5 \\
Delta & 88.7 & 80.7 & 93.6 & 7.1 \\
Rivers & 90.6 & 82.0 & 91.8 & 19.5 \\
Oyo & 89.2 & 56.5 & 81.7 & 9.9 \\
Osun & 97.8 & 82.9 & 95.1 & 13.4 \\
Lagos & 92.0 & 95.7 & 97.9 & 27.9 \\
Sokoto & 92.8 & 20.4 & 42.8 & 2.7 \\
Kano & 90.4 & 29.0 & 65.8 & 2.9 \\
Zamfara & 95.9 & 10.1 & 32.8 & 2.4 \\
Borno & 86.0 & 21.6 & 35.7 & 1.5 \\
Yobe & 81.9 & 17.6 & 33.4 & 2.1 \\
Gombe & 96.8 & 52.6 & 71.6 & 8.9 \\
Benue & 86.7 & 31.6 & 66.6 & 8.1 \\
Kwara & 92.0 & 54.4 & 84.1 & 9.0 \\
Niger & 95.8 & 50.1 & 82.0 & 11.3 \\
FCT & 98.0 & 75.8 & 85.5 & 22.4 \\
Urban & 95.2 & 83.6 & 93.5 & 21.1 \\
Rural & 90.0 & 40.2 & 65.8 & 3.5 \\
National & 91.4 & 51.6 & 73.1 & 8.1 \\
\hline Soure: & $985 N$. & &
\end{tabular}

Source: NBS/CBN/NCC Socio-economic survey on Nigeria, 2008 
Table 15: Electrical appliances based ownership categorization

\begin{tabular}{|c|c|c|c|}
\hline Level & Appliance & Wattage (W) & Wattage x df \\
\hline C1 & Radio & 2 & 2 \\
\hline C2 & Phone charger & 12 & 12 \\
\hline C3 & Table fan & 70 & 70 \\
\hline $\mathrm{C} 4$ & Light 1 & 56 & 56 \\
\hline C5 & Light 2 & 28 & 28 \\
\hline C6 & Ceiling fan & 120 & 120 \\
\hline C7 & Television & 150 & 150 \\
\hline C8 & $\mathrm{PC}$ & 300 & 300 \\
\hline C9 & Luxury & 500 & 500 \\
\hline $\mathrm{C} 10$ & Iron & 1000 & 1000 \\
\hline \multicolumn{4}{|c|}{ Combined levels ( $\mathrm{df}=0.7$ ) } \\
\hline C11 & $\mathrm{C} 1+\mathrm{C} 2$ & 14 & 9.8 \\
\hline $\mathrm{C12}$ & $\mathrm{C} 1+\mathrm{C} 3$ & 72 & 50.4 \\
\hline C13 & $\mathrm{C} 1+\mathrm{C} 5$ & 30 & 21 \\
\hline C14 & $\mathrm{C} 1+\mathrm{C} 4$ & 58 & 40.6 \\
\hline C15 & $\mathrm{C} 2+\mathrm{C} 3$ & 82 & 57.4 \\
\hline C16 & $\mathrm{C} 2+\mathrm{C} 5$ & 40 & 28 \\
\hline C17 & $\mathrm{C} 1+\mathrm{C} 2+\mathrm{C} 3+\mathrm{C} 5$ & 112 & 78.4 \\
\hline C18 & $\mathrm{C} 17+\mathrm{C} 7$ & 262 & 183.4 \\
\hline C19 & $\mathrm{C} 18+\mathrm{C} 9$ & 762 & 533.4 \\
\hline $\mathrm{C20}$ & $\mathrm{C} 1+\mathrm{C} 2+\mathrm{C} 5+\mathrm{C} 6+\mathrm{C} 7$ & 312 & 218.4 \\
\hline $\mathrm{C} 21$ & $\mathrm{C} 20+\mathrm{C} 9$ & 812 & 568.4 \\
\hline $\mathrm{C} 22$ & $\mathrm{C} 20+\mathrm{C} 10$ & 1312 & 918.4 \\
\hline $\mathrm{C} 23$ & $\mathrm{C} 20+\mathrm{C} 8$ & 612 & 428.4 \\
\hline
\end{tabular}

$\mathrm{df}=1$ for the uncombined levels

Table 16: Electricity rates as specified by NERC

\begin{tabular}{lllll}
\hline Customer classification & \multicolumn{2}{c}{$R 1$} & \multicolumn{2}{c}{$R 2$} \\
\hline Disco Zone & $\boldsymbol{P}_{\boldsymbol{u}}(\mathbf{A} / \boldsymbol{k} \boldsymbol{W h})$ & $\boldsymbol{M}_{\boldsymbol{f c}}(\mathrm{A})$ & $\boldsymbol{P}_{\boldsymbol{u}}(\mathbf{A} / \boldsymbol{k} \boldsymbol{W h})$ & $\boldsymbol{M}_{\boldsymbol{f c}}(\mathrm{A})$ \\
\hline Eko & 4.0 & - & 15.63 & 750.00 \\
Enugu & 4.0 & - & 16.44 & 650.00 \\
Ibadan & 4.0 & - & 16.11 & 624.95 \\
Ikeja & 4.0 & - & 13.21 & 750.00 \\
Jos & 4.0 & - & 16.75 & 775.00 \\
Kaduna & 4.0 & - & 17.00 & 781.13 \\
Kano & 4.0 & - & 16.01 & 666.89 \\
Port Harcourt & 4.0 & - & 15.09 & 700.00 \\
Yola & 4.0 & - & 15.00 & 750.00 \\
Benin & 4.0 & - & 14.82 & 750.00 \\
Abuja & 4.0 & - & 14.70 & 702.11 \\
\hline
\end{tabular}

Table 17: Review of selected papers on energy access in Nigeria (developing countries) References Review/contribution/summary 
in Nigeria

- Also strongly supports and advocates the use of renewable energy sources for power generation in Nigeria owing largely to the enormously untapped and sustained opportunity they provide for meeting Nigeria's electricity needs. Their environmental friendliness is also highlighted.

Some limitations to the full exploitation and harnessing of renewable energy (wind) in Nigeria were given as:

$>$ Low financing

$>$ Reluctance of government and its agents to encourage wind technologies

$>$ Lack of awareness

$>$ Technical ineptitude

Some strategies proffered for improvement

$\checkmark$ Creation of level playing field between renewable energy sources (wind) and other (fossil based) energy sources

$\checkmark$ Creation of a sustainable market for the sale of wind energy

$\checkmark$ Provision of interest free and low interest loans for the financing of wind energy projects

$\checkmark$ Development and maintenance of wind farms in areas of high potentials

[23] The authors posit that life of African residents (condition and standard of living) could be enhanced through the use of environmentally friendly renewable energy technologies such as solar power by underscoring the importance and providing a strong rationale for concerted political will, collaboration and transparent energy policies

Some highlighted strategies proposed include:

$\checkmark$ Collaboration between the developing countries (in Africa) to ensure the proper utilization and optimum harnessing of abundant and prevalent renewable energy technologies

$\checkmark$ Evolution of (practical and sustainable) schemes capable of guaranteeing the dispatch of citizens daily needs in both rural and urban areas through the use of renewable sources

[25] The author provides an overall analyses of the Nigeria power (electric) sector presenting its challenges and policy guideline(s) capable of guaranteeing the achievement of a world class standard power (electric) market and sustainable development

Some presented challenges confronting the Nigeria electricity sector include:

$>$ Poor maintenance and management

$>$ Vandalism of equipment

$>$ Poor energy investments and lack of competition

$>$ Corruption

As a guideline, the need for the focusing of more attention to the (enormous) renewable energy potentials in the country (as a means of diversifying and buoying our energy mix) is strongly advocated

[32] Present by simulation (RegCM3) useful data to show the effect of weather on


solar radiation in Nigeria as a way of providing additional data (information) during the computation of solar potential. The authors in their presentation aptly underscore the huge costs involved in grid expansion and the low electrical load (occasioned by low ownership) thus proposing the deployment of off-grid decentralized energy systems based on renewable energy sources and technologies (especially solar energy) with proven effectiveness in both rural and semi-urban areas of developing countries

[31] The authors here argue on the use of biomass for sustainable distributed generation of power to rural dwellers with limited access to grid electricity.

Exploring the wide-ranging potential of bioenergy resources in Nigeria for bioelectric power generation they provide useful statistics and contribution to the problem of the electrification of off grid rural communities.

[30] This paper contributes to the harnessing of wind energy potentials in Nigeria by evaluating the wind potential of seven selected locations in the Niger Delta Area of Nigeria.

A useful observation from the paper is the fact that Ogoja portends promising potentials (with specific wind turbines).

[27] Guarantees the viability, sustainability and diffusion of decentralized renewable energy technology investment in developing nations through the adoption of a cost-competitive energy pricing scheme.

It also highlights the fact that the proposed energy pricing scheme provides a platform for the incorporation of the different stakeholders in the planning process.

[26] The authors envision a looming energy crisis in sub-Saharan Africa (SSA) due to impending energy shortage.

They advocate for the full exploitation and harnessing of local renewable energy resources and present a comprehensive review of renewable energy in SSA, the regional status of renewable energy (RE) applications and also underscores the necessity of RE power generation integration planning from a management perspective.

Conceptual challenges affecting RE integration in SSA include:

$>$ Limited capital investment

$>$ Lack of technological knowledge on RE development

$>$ Constricted power generation planning

$>$ Low rate of electrification in the area

$>$ High cost of electrical energy generation

High transmission losses

[38] Underscores the need for full exploitation and promotion of renewable energy resources as panacea to the problem of energy (electricity) access while arguing that increasing the share of renewable energy resources (RES) in the energy balance enhances sustainability and helps to improve the security of energy supply by reducing dependence on imported energy sources.

[14] The authors advocate the adoption of solar energy in diversifying our energy mix. In doing this, they carried out an examination of solar energy utilization as a renewable energy option in Nigeria from the point of sustainable development. Also investigated were the different applications to which solar resources have 


\begin{tabular}{|c|c|}
\hline & $\begin{array}{l}\text { been put to use, their extent of utilization, possible motivation for development of } \\
\text { solar energy conversion systems in Nigeria, barriers and challenges and possible } \\
\text { policy measures capable of mitigating these barriers and facilitating the utilization } \\
\text { of solar energy in Nigeria. }\end{array}$ \\
\hline [21] & $\begin{array}{l}\text { Critically assessed were the various policy issues on sustainable energy } \\
\text { development in Nigeria with the need for an amendment of some existing energy } \\
\text { laws to promote renewable energy strongly highlighted }\end{array}$ \\
\hline$[24]$ & $\begin{array}{l}\text { This study was carried out to gauge the effect of different penetration rate of } \\
\text { renewables in Nigeria's energy mix in order to provide useful information that } \\
\text { would help in future policy formulations in the Nigeria electricity sector. Shown } \\
\text { explicitly is the range of possible trade-offs between environmental impacts and } \\
\text { economic costs both in the short and long term. }\end{array}$ \\
\hline$[22]$ & $\begin{array}{l}\text { The authors strongly argue that for Nigeria to join the league of } 20 \text { most } \\
\text { industrious nations by } 2020 \text {, then access to clean and stable electricity is essential } \\
\text { as no country can sustain development if a greater proportion of its population } \\
\text { lack access to stable electricity supply. } \\
\text { The paper also summarizes pertinent literature on current energy issues in Nigeria } \\
\text { introducing the difficulty of the issues involved. } \\
\text { In carrying out its analyses via simulation using the LEAP system, current as well } \\
\text { as future expansion plans of the government in a } 20 \text { years period including the } \\
\text { introduction of new electricity generation technologies that have not been used in } \\
\text { the base year (2010) were included. }\end{array}$ \\
\hline [19] & $\begin{array}{l}\text { - This paper highlights the potentials of renewable energy in Nigeria by } \\
\text { reviewing some RES and showing how they can be tapped for useful and } \\
\text { uninterrupted electric energy supply } \\
\text { - Policies that could incentivize the realization of [a much] wider renewable } \\
\text { energy applications [especially] in rural Nigeria are examined and } \\
\text { reviewed } \\
\text { - The authors also discuss the challenges and future prospects of RE } \\
\text { positing that the dissemination of decentralized renewable energy } \\
\text { resources will not only improve the well-being of the Nigerian community } \\
\text { but will also enhance the energy and economic prospects of Nigerians for } \\
\text { potential global investments }\end{array}$ \\
\hline [39] & $\begin{array}{l}\text { - This paper discusses clean energy potentials in Nigeria with emphasis on } \\
\text { the obstacles to and stimulants of clean energy implementation and } \\
\text { renewable energy policies in Nigeria. } \\
\text { - The authors further highlight the huge potentials for the deployment of } \\
\text { solar photovoltaic (PV) and thermal systems in off-grid, grid connected } \\
\text { and hybrid configurations. }\end{array}$ \\
\hline [40] & $\begin{array}{l}\text { - The authors highlight the abundant renewable energy resources in Nigeria } \\
\text { and underscore continued underutilization of the renewable energy } \\
\text { sources. } \\
\text { - The paper presents the comparison of renewable energy development in } \\
\text { Nigeria with four (4) other sub-Saharan African countries. }\end{array}$ \\
\hline [41] & $\begin{array}{l}\text { - This paper presents the existing renewable energy technologies in Nigeria } \\
\text { and provides critical recommendations to further induce development of }\end{array}$ \\
\hline
\end{tabular}


renewable and sustainable energy systems based on autonomous energy systems and micro-grid technologies.

Table 18: 2005 Access to electricity of selected African countries

\begin{tabular}{|c|c|c|c|}
\hline Country & Electrification rate $(\%)$ & $\begin{array}{l}\text { Population without electricity } \\
\text { (million) }\end{array}$ & $\begin{array}{l}\begin{array}{l}\text { Population with } \\
\text { (million) }\end{array} \\
\end{array}$ \\
\hline Nigeria & 46 & 71.1 & 60.5 \\
\hline Algeria & 98.1 & 0.6 & 32.3 \\
\hline Egypt & 98 & 1.5 & 72.4 \\
\hline South Africa & 70 & 14 & 32.6 \\
\hline
\end{tabular}

Source: see ref [26]

Table 19: Population and land area of selected African countries

\begin{tabular}{lll}
\hline Country & 2005 population (million) & Land area (sq. km) \\
\hline Algeria & 33.96 & 2381740 \\
Egypt & 71.78 & 995450 \\
Nigeria & 138.59 & 910770 \\
South Africa & 47.64 & 1213090 \\
\hline
\end{tabular}

Source: World Bank Data Indicators

Table 20: installed capacity, net generation and distribution loss in Nigeria electricity industry for selected years

\begin{tabular}{llllll}
\hline Year & Installed capacity $\mathbf{( M W )}$ & Total net generation $(\mathbf{M W})$ & Load factor & Distribution loss (MW) & Loss ratio (\%) \\
\hline $\mathbf{1 9 8 0}$ & 2507 & 783.9 & 31.3 & 239.0 & 30.5 \\
$\mathbf{1 9 8 1}$ & 2755 & 895.0 & 32.5 & 234.0 & 26.1 \\
$\mathbf{1 9 8 2}$ & 2872 & 929.2 & 32.4 & 236.5 & 25.5 \\
$\mathbf{1 9 8 3}$ & 3192 & 945.5 & 29.6 & 239.0 & 25.3 \\
$\mathbf{1 9 8 4}$ & 3572 & 978.7 & 27.4 & 273.3 & 27.9 \\
$\mathbf{1 9 8 5}$ & 4192 & 1133.4 & 27.0 & 383.3 & 33.8 \\
$\mathbf{1 9 9 0}$ & 5958 & 1373.2 & 23.0 & 445.4 & 32.4 \\
$\mathbf{1 9 9 1}$ & 5959 & 1554.0 & 26.1 & 607.8 & 39.1 \\
$\mathbf{1 9 9 2}$ & 5881 & 1626.4 & 27.7 & 653.2 & 40.2 \\
$\mathbf{1 9 9 3}$ & 5881 & 1588.2 & 27.0 & 632.4 & 39.8 \\
$\mathbf{1 9 9 4}$ & 5881 & 1698.3 & 28.9 & 774.1 & 45.6 \\
$\mathbf{1 9 9 5}$ & 5881 & 1585.5 & 27.0 & 682.8 & 43.1 \\
$\mathbf{2 0 0 0}$ & 5888 & 1613.1 & 27.4 & 641.3 & 39.8 \\
$\mathbf{2 0 0 1}$ & 5888 & 1693.7 & 28.8 & 683.4 & 40.4 \\
$\mathbf{2 0 0 2}$ & 5888 & 2163.6 & 36.7 & 726.4 & 33.6 \\
$\mathbf{2 0 0 3}$ & 5898 & 2209.1 & 37.5 & 769.3 & 34.8 \\
$\mathbf{2 0 0 4}$ & 5898 & 2645.0 & 44.8 & 861.3 & 32.6 \\
$\mathbf{2 0 0 5}$ & 5898 & 2571.2 & 43.6 & 637.0 & 24.8 \\
$\mathbf{2 0 0 8}$ & 5898 & 2409.8 & 40.9 & 227.1 & 9.4 \\
\hline
\end{tabular}

Source: see ref [25] 
Table 21: Projected electricity demand (MW) for Nigeria

\begin{tabular}{lllllll}
\hline Scenario & 2005 & 2010 & 2015 & 2020 & 2025 & 2030 \\
\hline Reference (7\%) & 5,746 & 15,730 & 28,360 & 50,820 & 77,450 & 119,200 \\
High growth (10\%) & 5,746 & 15,920 & 30,210 & 58,180 & 107,220 & 192,000 \\
Optimistic (11.5\%) & 5,746 & 16,000 & 31,240 & 70,760 & 137,370 & 250,000 \\
Optimistic (13\%) & 5,746 & 33,250 & 64,200 & 107,600 & 172,900 & 297,900 \\
\hline
\end{tabular}

Table 22: Customer load distribution

\begin{tabular}{lll}
\hline S/N & Category of customer & \% of consumption \\
\hline 1 & Residential & 60 \\
2 & Commercial & 24 \\
3 & Industrial & 12 \\
4 & Customer on special tariff & 1.4 \\
5 & Street lighting & 0.6 \\
6 & Power export & 2 \\
7 & Total & 100 \\
\hline
\end{tabular}

Table 23: Max, min and mean yearly solar radiation potential plot

\begin{tabular}{llll}
\hline \multirow{2}{*}{ Month } & \multicolumn{3}{l}{ Solar radiation potential $\left(\mathbf{k W} \mathbf{~ h} / \mathbf{m}^{2}\right.$ day $)$} \\
\cline { 2 - 4 } & Maximum & Minimum & Mean \\
\hline January & 6.07 & 5.43 & 5.77 \\
February & 6.01 & 5.18 & 5.75 \\
March & 6.80 & 4.90 & 5.98 \\
April & 6.92 & 4.71 & 5.91 \\
May & 6.95 & 4.47 & 5.71 \\
June & 7.01 & 4.03 & 5.29 \\
July & 6.47 & 3.69 & 4.78 \\
August & 6.25 & 3.54 & 4.52 \\
September & 6.39 & 3.68 & 4.78 \\
October & 6.43 & 4.16 & 5.24 \\
November & 5.99 & 4.47 & 5.41 \\
December & 5.62 & 4.93 & 5.41 \\
\hline
\end{tabular}

Source: see ref [44]

Table 24: Target for solar energy contribution (MW) to electricity generation in Nigeria

\begin{tabular}{llll}
\hline Resource & Short & Medium & Long \\
\hline Solar PV & 5 & 120 & 500 \\
Solar Thermal & - & 1 & 5 \\
\hline
\end{tabular}

Source: see ref [46]

Table 25: Some pilot solar based projects in Nigeria

\begin{tabular}{lll}
\hline Location & Project & Capacity \\
\hline Udu, Sokoto & Solar PV internet backup at Nunet & \\
UDUTH, Sokoto & Community based pilot-water heater, Gynae lying in ward & 1000 litres \\
Enugu State & Solar rice dryer & 2 tonnes \\
UDUTH, Sokoto & Solar water heating system at the maternity ward & 1000 litres
\end{tabular}


SERC demonstration area Riser and spiral water heater

Source: see ref [46]

Table 26: small hydro projects and their potentials in Nigeria

\begin{tabular}{llllll}
\hline State (pre 1980) & River basin & Total sites & Developed (MW) & Underdeveloped (MW) & Total capacity (MW) \\
\hline Sokoto & Sokoto - Rima & 22 & 8.0 & 22.6 & 30.6 \\
Katsina & Sokoto - Rima & 11 & & 8.0 & 8.0 \\
Niger & Niger & 30 & & 117.6 & 117.6 \\
Kaduna & Niger & 19 & & 59.2 & 59.2 \\
Kwara & Niger & 12 & & 38.8 & 38.8 \\
Kano & Hadeija - Jamaare & 28 & 6.0 & 40.2 & 46.2 \\
Borno & Chad & 28 & & 20.8 & 20.8 \\
Bauchi & Upper Benue & 20 & & 42.6 & 42.6 \\
Gongola & Upper Benue & 38 & & 162.7 & 162.7 \\
Plateau & Lower Benue & 32 & 18.0 & 92.4 & 110.4 \\
Benue & Lower Benue & 19 & & 69.2 & 69.2 \\
Cross River & Cross River & 18 & & 28.1 & 28.1 \\
\hline Total & & $\mathbf{2 7 7}$ & $\mathbf{3 2}$ & $\mathbf{7 0 2 . 2}$ & $\mathbf{7 3 4 . 2}$ \\
\hline
\end{tabular}

Source: see ref[19]

Table 27: small HEP stations classification

\begin{tabular}{ll}
\hline Classification & Size \\
\hline Pico & $<5 \mathrm{~kW}$ \\
Micro & $5 \mathrm{~kW}-100 \mathrm{~kW}$ \\
Mini & $100 \mathrm{~kW}-1 \mathrm{MW}$ \\
Small & $1 \mathrm{MW}-30 \mathrm{MW}$ \\
\hline
\end{tabular}

Table 28: Electricity dispatch ability of classified SHSs among various households

\begin{tabular}{c|ccccc}
\hline & CL 1 & CL & CL 3 & CL 4 & CL 5 \\
& $(70 \mathrm{Wh})$ & $(120 \mathrm{Wh})$ & $(300 \mathrm{Wh})$ & $(400 \mathrm{Wh})$ & $(550 \mathrm{Wh})$ \\
\hline ELBEC & $\checkmark$ & $\checkmark$ & $\checkmark$ & $\checkmark$ & $\checkmark$ \\
MLBEC & $\checkmark$ & $\checkmark$ & $\checkmark$ & $\checkmark$ & $\checkmark$ \\
MxBEC & $\bullet$ & $\checkmark$ & $\checkmark$ & $\checkmark$ & $\checkmark$ \\
ELMEC & $\bullet$ & $\checkmark$ & $\checkmark$ & $\checkmark$ \\
SLMEC & $\bullet$ & $\bullet$ & $\bullet$ & $\checkmark$ \\
LLMEC & $\bullet$ & $\checkmark$ & $\checkmark$ & $\bullet$ & $\bullet$ \\
\hline
\end{tabular}

Table key

$\checkmark$ Implies that the SHS is capable of dispatching the entire electricity demand of the household;

- Implies that the SHS is capable of dispatching a sizeable fraction of the household's electricity demand though an upgrade is needed.

* Implies that the household needs to upgrade its SHS to meet its current electricity demand 
Table 29: SHS mobility of households (in watts)

\begin{tabular}{l|ccccc}
\hline & CL 1 & CL 2 & CL 3 & CL 4 & CL 5 \\
\hline CL 1 & 0 & 30 & 210 & 310 & 460 \\
CL 2 & -30 & 0 & 180 & 280 & 430 \\
CL 3 & -210 & -180 & 0 & 100 & 250 \\
CL 4 & -310 & -280 & -100 & 0 & 150 \\
CL 5 & -460 & -450 & -250 & -150 & 0 \\
\hline
\end{tabular}

